\title{
Development of the human mandible under the influence of the environment and/or genetics
}

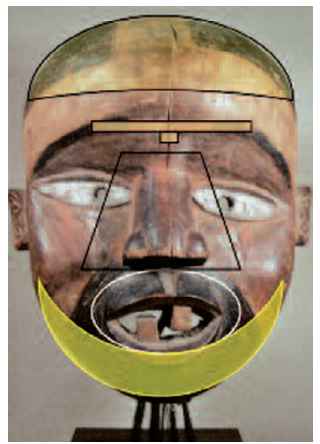

\section{Roland BENOÎT}

\author{
ABSTRACT \\ for this malformation.

\section{KEY WORDS} \\ Systemic biology, \\ Mandible, \\ Promandibulia, \\ Interactions, \\ Integrations, \\ Gene therapy.
}

Researchers conduct their studies of the mandible by placing it in the "exploitable" framework of systemic biology. They investigate an anomaly of its development, promandibulia, or mandibular prognathism, within this context, by studying molecular and cellular reactions at the level of their constitutive elements and their integration during the course of mandibular development. Here we propose a new etiological and therapeutic approach

\section{1 - INTRODUCTION}

For years many clinicians have noted that decisions for electing a therapeutic strategy for certain malformations, typically Class III skeletal cases, for young patients can be uncertain and, because a reliable diagnosis cannot be made, have a prognosis hemmed by risks. These treatments, begun early with orthopedic devices, usually 


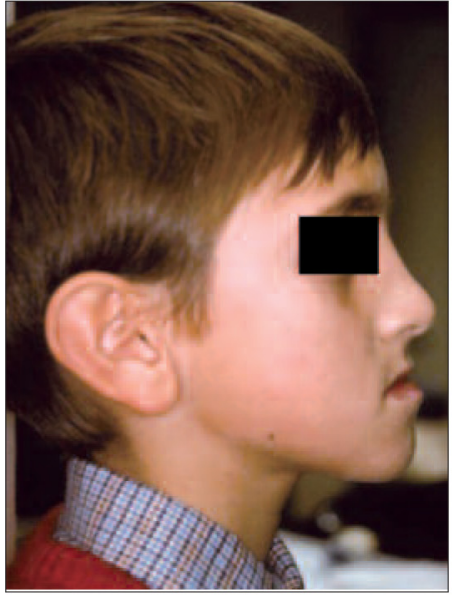

a

9 years

a: M. Langlade. Prediction of long-term growth, 1999;

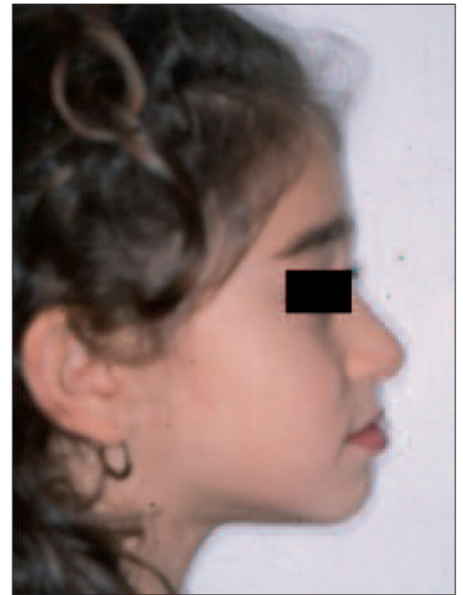

6 years

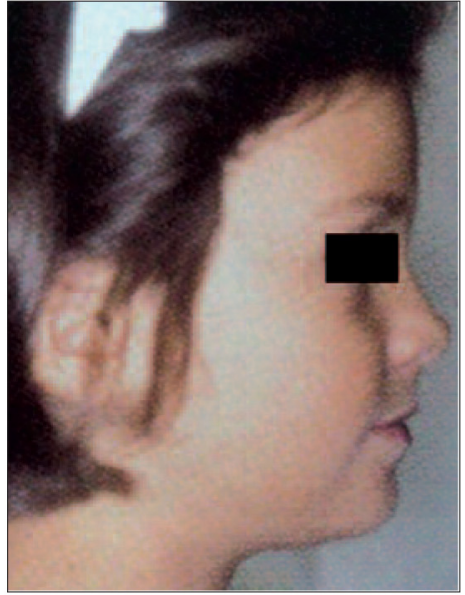

7 years

Figures 1a to $1 \mathrm{C}$

b: MJ. Deshayes. Early diagnosis, 2006;

c: M. Raberin et al. Cephalometric decisional factors, 2007.

followed by orthodontic therapy, often conclude when patients are about 20 years old with a surgical procedure. Today, this course of events has become unacceptable from both an economic and an ethical point of view.

To discern an alternative, M. Langlade in $1999^{16,17}$, M.-J. Deshayes in $2000^{13}$, and M. Raberin in $2007^{24}$ proposed the use of cephalometric decisional factors (fig. 1).

Now in the 21st century, orthodontists must pursue this line of thought and conceive of ways to transform our specialty. We must employ the resources of biomedical sciences to improve our technologies and, more than that, take into account the changes that marked our society and the economics of health care.

\section{2 - BIOLOGY OF SYSTEMS OR SYSTEMIC BIOLOGY}

Our professions, our specialties need to learn how biology can help us to understand better the advances it has recently made and how we can establish an inventory of the astonishing therapeutic possibilities that has made available to us.

Since 1970, developmental biology has aroused an enormous amount of interest in genetic diagnosis and given rise to hopes for the utilization of genetic and stem cell therapy ${ }^{5}$. However, the complexity of the cervico-cranio-facial region has obliged us to reflect on the possibilities of a new biology better equipped to describe in closer detail the complexity of the phenomena of development and its integration. 


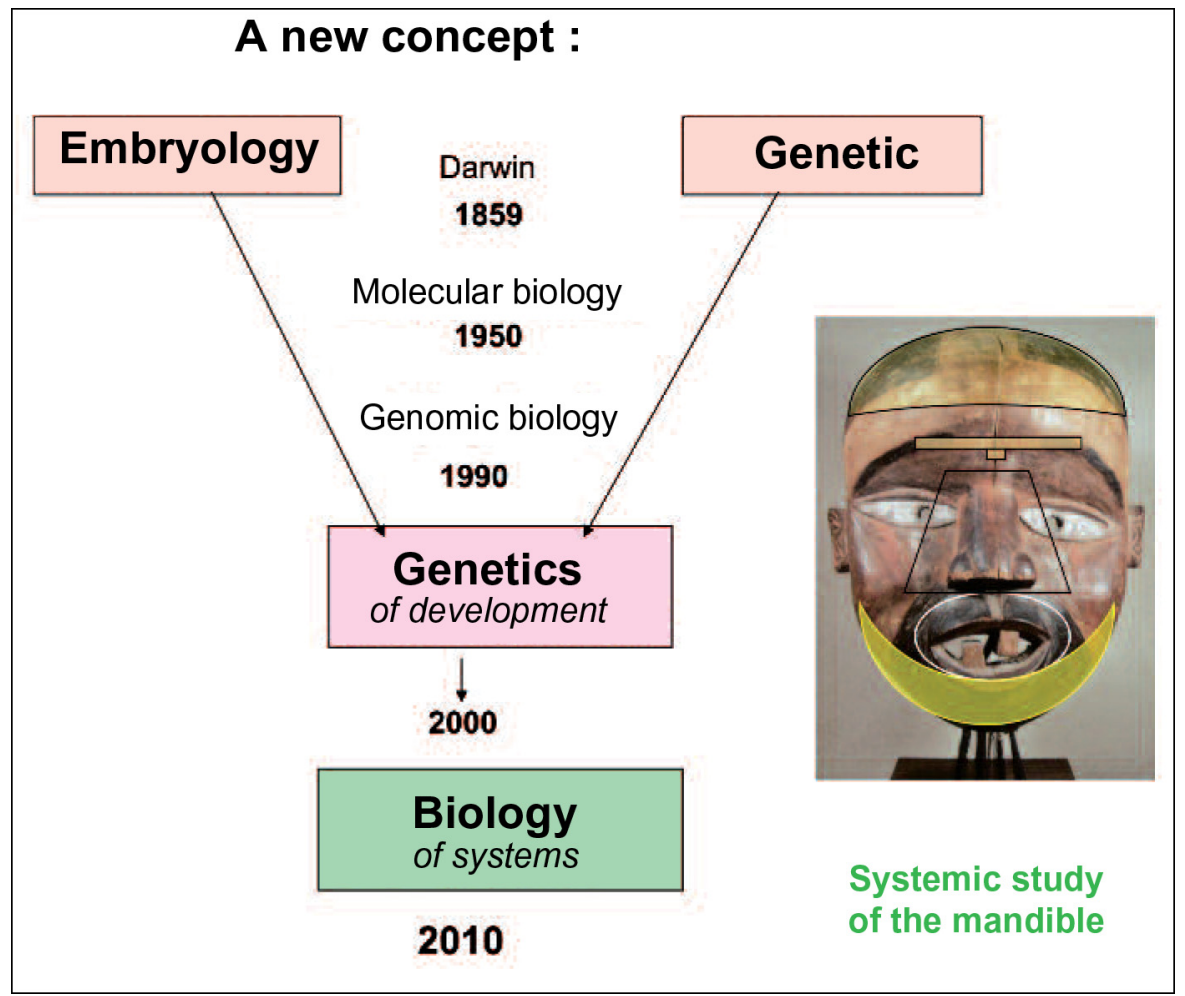

Figure 2

In the particular field of embryonic, fetal, and adolescent cervico-craniofacial development it would be futile to seek immediate perfect understanding of the relationships between morphological, genetic, immunological, endocrinological, environmental, orthodontic, mechanical, and many other important factors. We must begin the effort by focusing our efforts singly, on each sector of this complex domain in a new approach ${ }^{7}$.

The complexity and the multi-level organization of the head demand that we examine it with a systemic biological approach in order to understand it. In this view the goal then becomes how to imagine this multi-level organization that allows all systems to function $^{15}$.
Systems biology has for its objective the study, in isolation, of systems formed by genes in interactions, considering all the elementary systems and then their level of integration in a system with limits that are broad and well defined ${ }^{9}$.

"In basic bio-medical research systems biology is today the acknowledged paradigm of choice for understanding the emerging properties of complex biological systems" 8 (fig. 2) In our specialty, systems biology can be applied to the normal and the pathological development of different systems such as the neurocranial, the naso-maxillary, the dentoalveolar, the mandibular and others still to be defined. 


\section{3 - SYSTEMIC BIOLOGY OF THE MANDIBLE}

The mandible is a complex system within the face. How can researchers extend their studies of this structure? They must devote themselves to placing it an exploitable framework. It is necessary, for example, to construct a model within which all our current biological and other applicable scientific knowledge can be integrated. The mandible itself is composed of different biological systems, skeletal, muscular, vascular, and nervous. Interactions between products of genes form each one of these elemental systems. Later, integration of these symptoms, at different levels, occurs in the defined and functioning mandible.

Every year eight million children, $6 \%$ of all worldwide births, are born with a serious defect that is confirmed to be genetic or partially genetic in ori$\operatorname{gin}^{15}$. These deformities vary widely in nature, promandibulia being the best-known facial anomaly. Its frequency varies with populations, affecting $1 \%$ of Caucasians but in a higher rate in Spain and North Africa and afflicting $15 \%$ of Asian children ${ }^{27}$.

In this article we shall focus on the latest research based genetic and biological information about the mandibular system and illustrate this data with three clinical cases that illuminate current therapeutic procedures.

\section{Genetics and the mandible}

After the discovery of development genes in the second half of the 20th century in studies first of drosophila flies, then of mice, and finally in human embryos the description of homeotic genes led to an understanding of the mechanisms of development through segments or morphological fields preparing the way for a "pattern" of organization of the body into the head, the torso, and the limbs. In this conception the head is organized:

- in an anterior field organized by the expression of "architect" genes called non-Hox whose posterior limit is located between the R2 and $\mathrm{R} 3$ rhombomeres of the neural plate;

- a posterior field directly behind the anterior field that is organized by expression of the Hox "architected" genes, which will be responsible for the positioning of the osseous tissue of the mandible and the osteoblastic differentiation in two fields and, as a result, of the adult structures that derive from it ${ }^{4,12}$.

These procedures are responsible for the skeletal structure of the mandible defining the frontiers between fields in both children and adults from the Hox and the non-Hox genetic expressions. In the cranium or in a radiological image of an adult, the limits between the two fields can be materialized sagittally by placement of lines joining landmark points lambda and ephippion and one joining ephippion to the mandibular canal, which is the limit of the insertion of the sphenomandibular ligament (fig. 3). The angle formed by these two lines makes it possible to visualize and to measure modifications of phenotypes in the expression of the rhombomeric HOX genes, which define the ramal portion of the mandible 6 (fig. 3) 


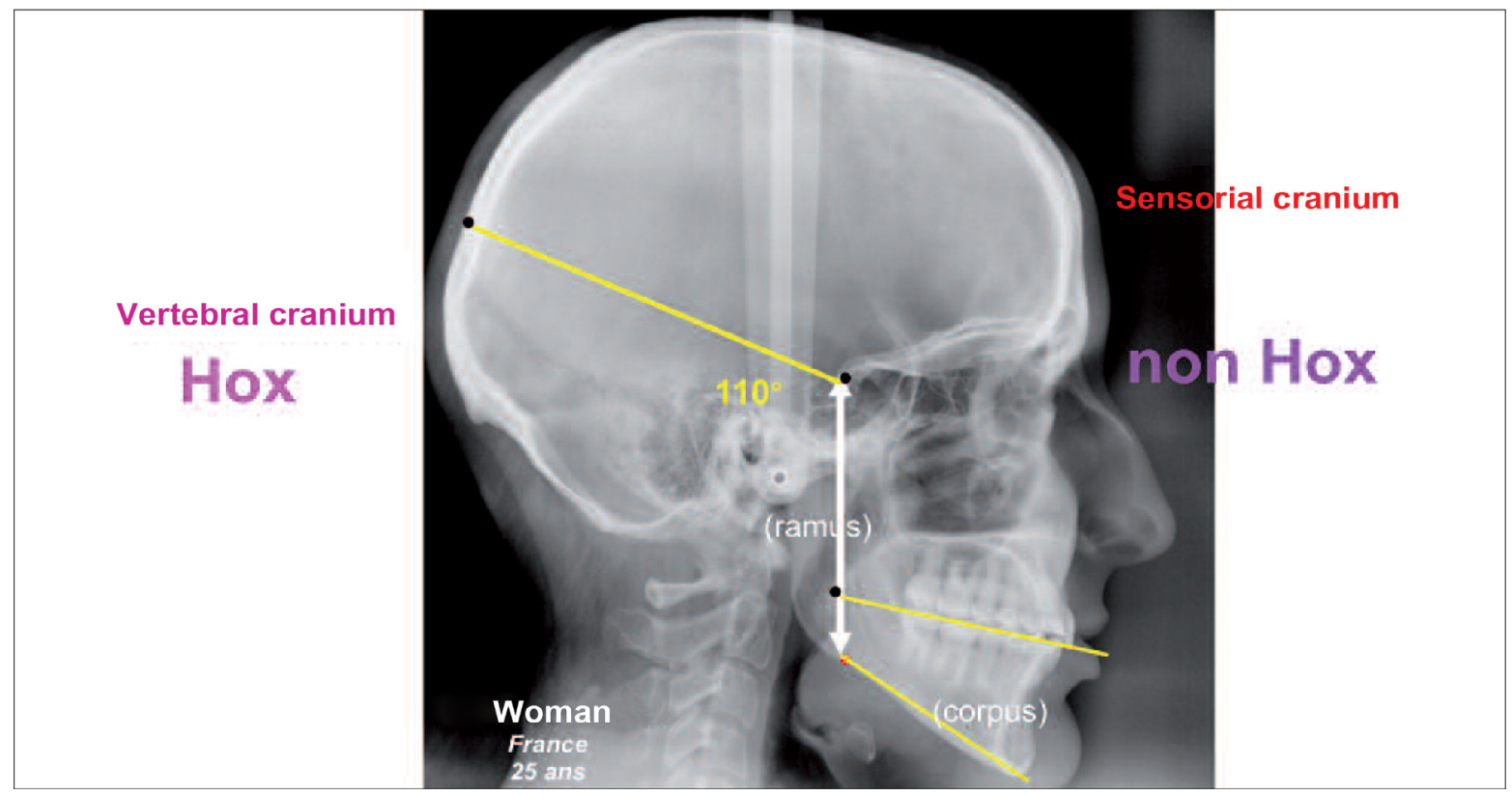

Figure 3

Limits of the fields in which the Hox genes express themselves.

R. Benoit. Biom. Hum. et Anthropol. 2008: 26 (1-2): 107-116.

- Christelle, 21 years old (fig. 4 to 8) This young woman consulted us because she wanted her irregular anterior teeth aligned. She complained of slight TMJ pain. She had undergone orthodontic treatment between the ages of 10 and 13 that had probably failed to create stable inter-arch relationships or correct physiological muscular action.

Our clinical examination showed she had a Class III occlusion, a midline deviation of $3 \mathrm{~mm}$ to the right, and a slight anterior open bite, with the right laterals in edge-to-edge occlusion. Lateral movements were limited. Opening was also curtailed and accompanied by TMJ sounds in closure, which was accomplished by a "bayonet" movement. Contractions of the masseter muscles were not synchronous.

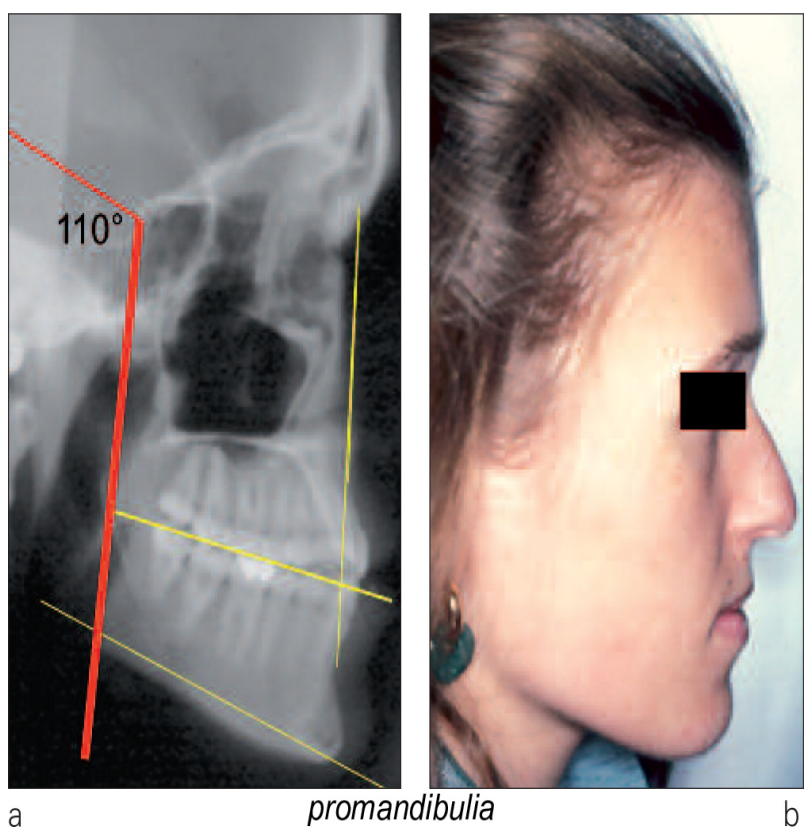

Figures $4 a$ and $4 b$ Christelle C., 21 years old. Environmental factors. 


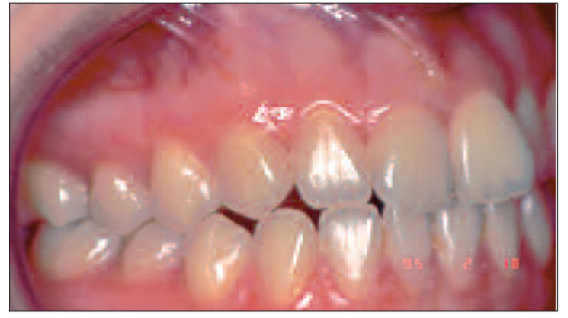

a

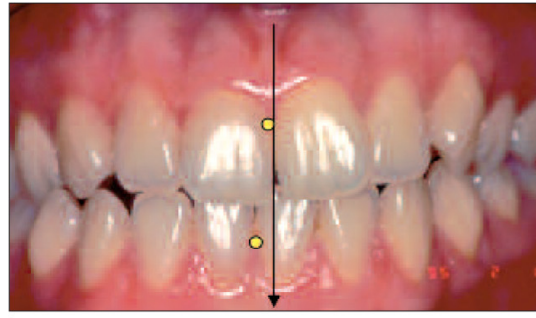

$\mathrm{b}$

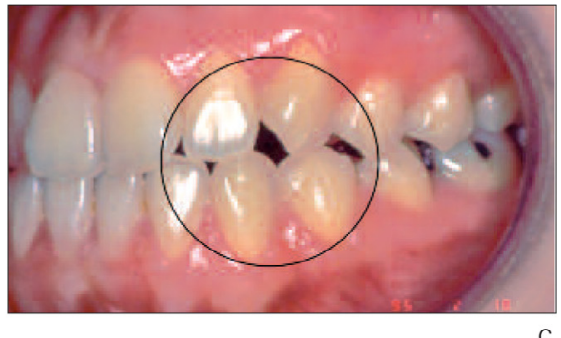

Figures 5a to $5 \mathrm{c}$

Christelle C., 21 years old. Inter-arch relationships.

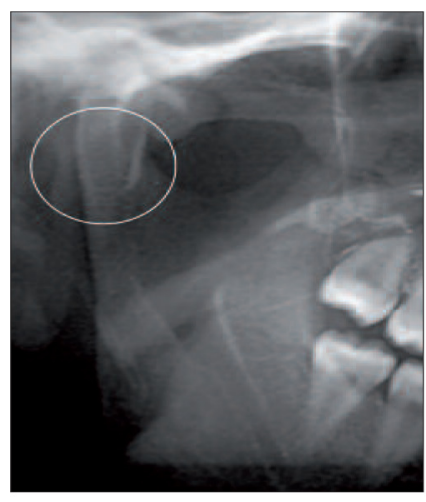

a

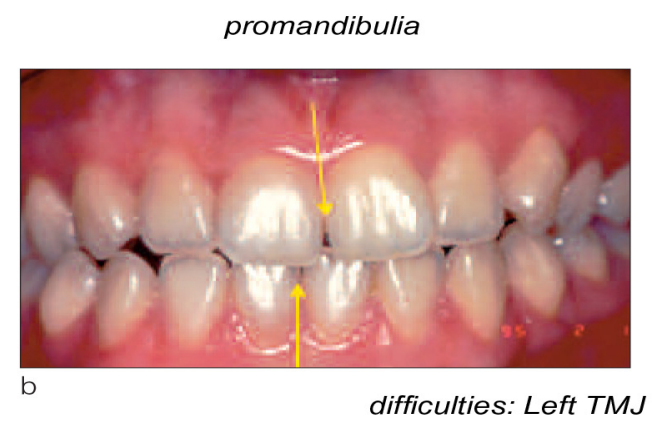

Figure 6a to $6 c$

Christelle C., 21 years old. Hypercondylia left side with different osseous density.

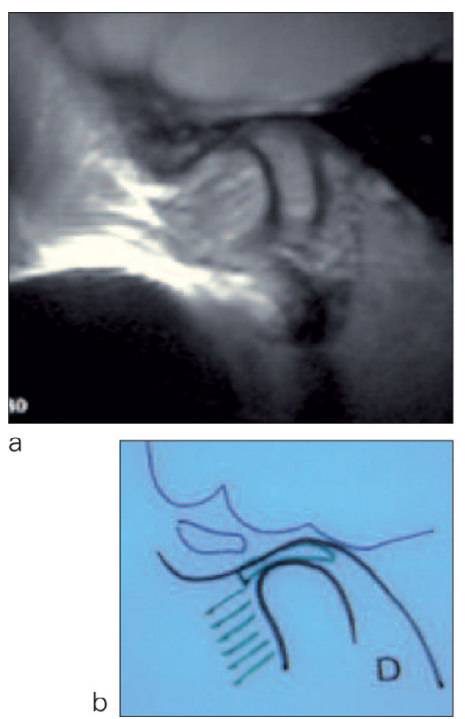

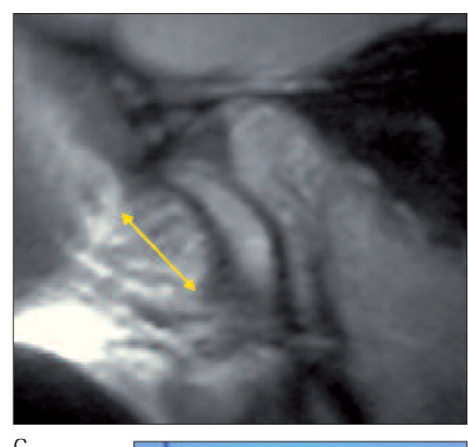

c

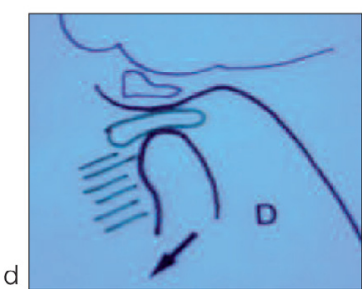

Figures $7 a$ to $7 d$

Christelle C., 21 years

old.

$M R I$ examination right side (beginning of treatment). 


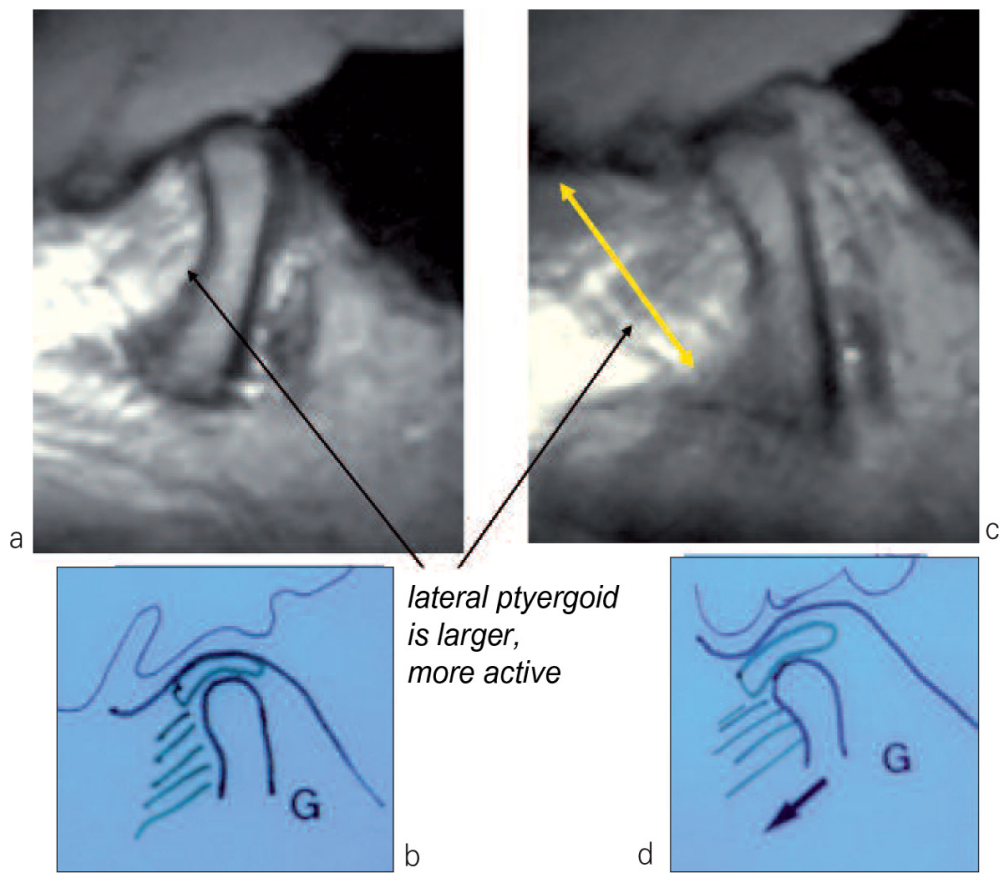

Radiologic examination confirmed the Class III status of her dentition and showed over-development of the left mandibular condyle.

MRI, Magnetic Resonance Imaging, of the TMJs, Temporo-MandibularJoints, in maximal inter-cuspation revealed that the right and left articular discs were in normal position. In opening movement of the mandible the articulation relationships remained normal but an insufficient translation of the left disc persisted. The left lateral ptyergoid muscle was larger and more active than the right because patient chews only on the right side.

- Nathalie, 18 years old (fig. 9 and 10)

This young woman is understandably highly concerned about her unsightly facial features (fig. 9 b) and the poor relationship between her upper and lower teeth. Our clinical examination revealed a serious
Figures 8 a to $8 d$

Christelle C., 21 years

old.

MRI examination left side (beginning of treatment). promandibulia and tense facial musculature. Inter-arch relationships were Angle Class III with depressed alveoli and open bites in the regions of the mandibular second bicuspids (the upper second bicuspids are congenitally absent). Articulation of the upper and lower second molars is abnormal.

The radiological examination confirmed the Class III skeletal status of the patient and a dentition that was marked by a retruded maxilla and a protruded mandible.

Temporo-mandibular articulation is normal but function of the masseter muscles is reduced while the tongue is more active than usual.

- Sylvain 19 years old (fig. 11 and 12)

This young man, who is now in treatment, consulted us because of his skeletal Class III condition in a hyperdivergent face (fig. 12 a). He had a 


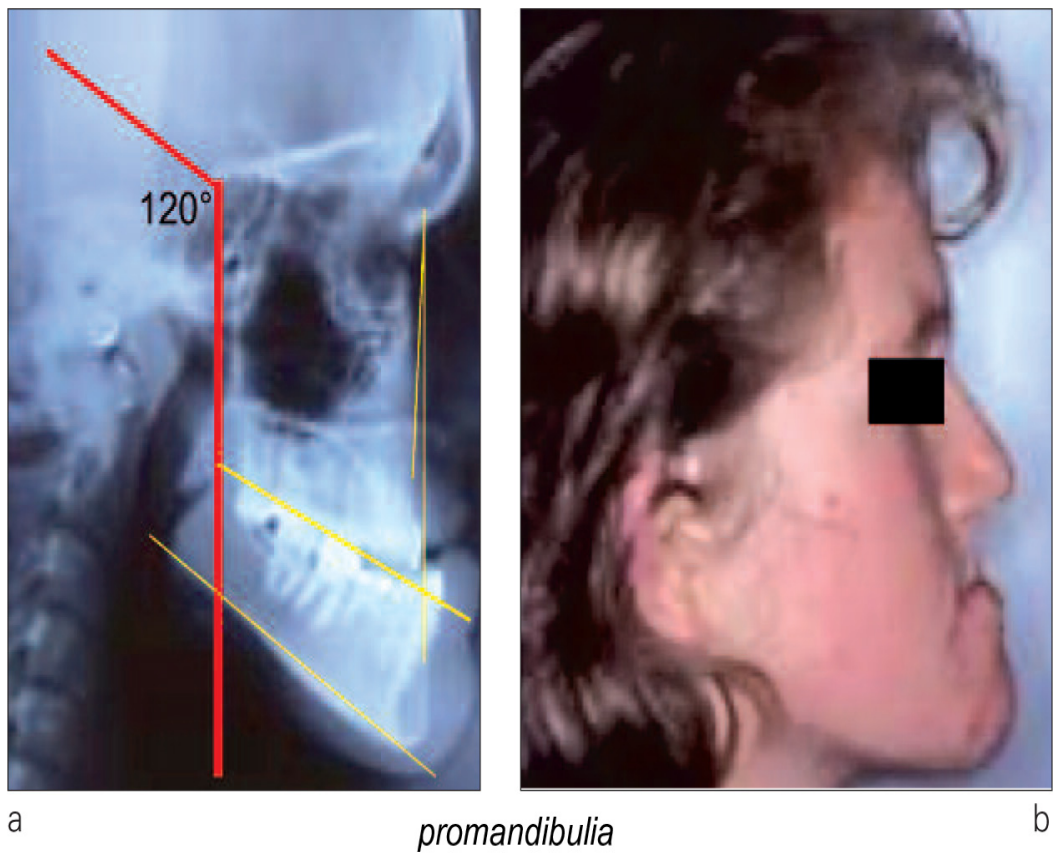

Figures $9 a$ and $9 b$

Nathalie P., 18 years old.

Genetic factors.

Syndrome?
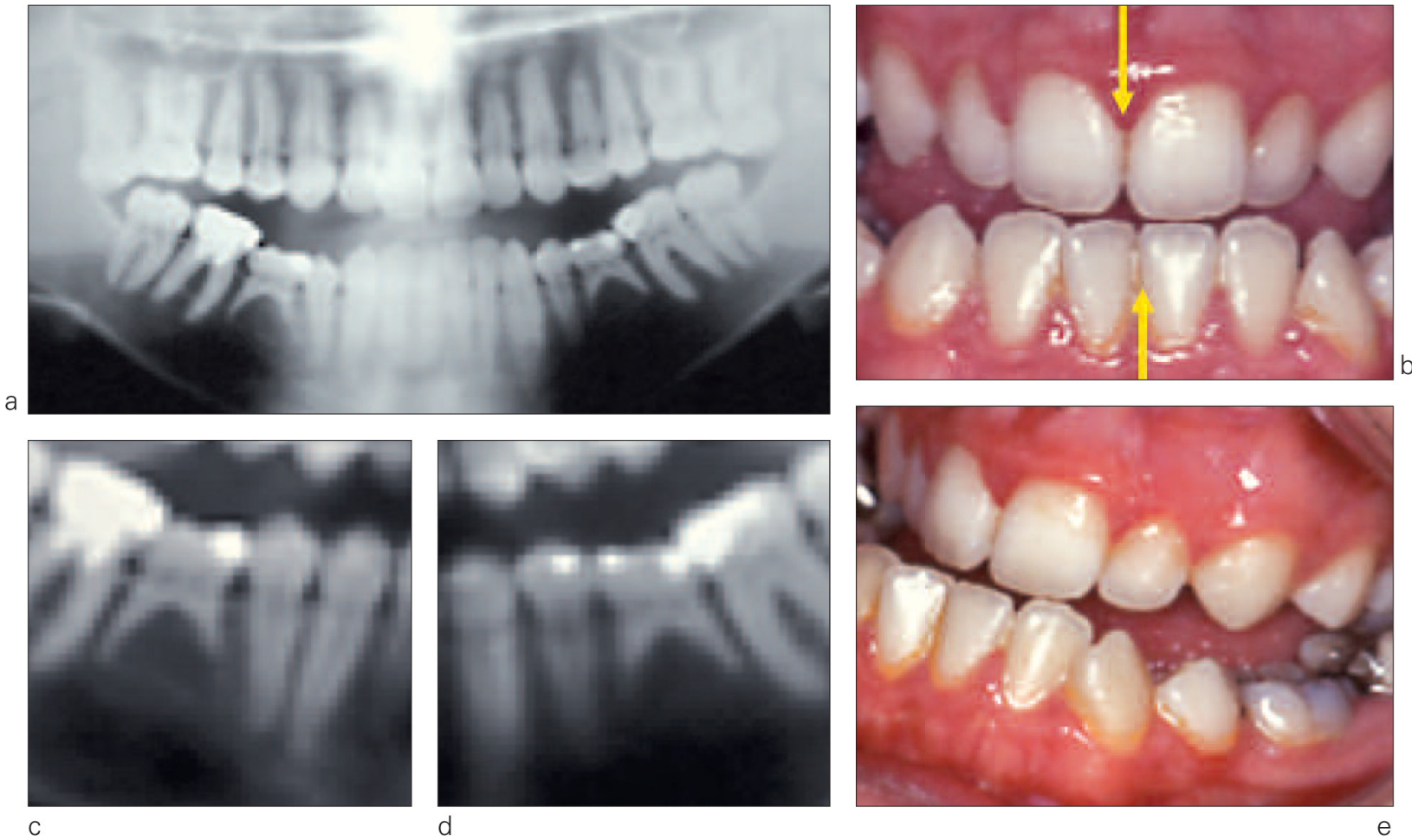

Figures 10a to $10 e$

Nathalie P., 18 years old. Agenesis of lower second bicuspids. 

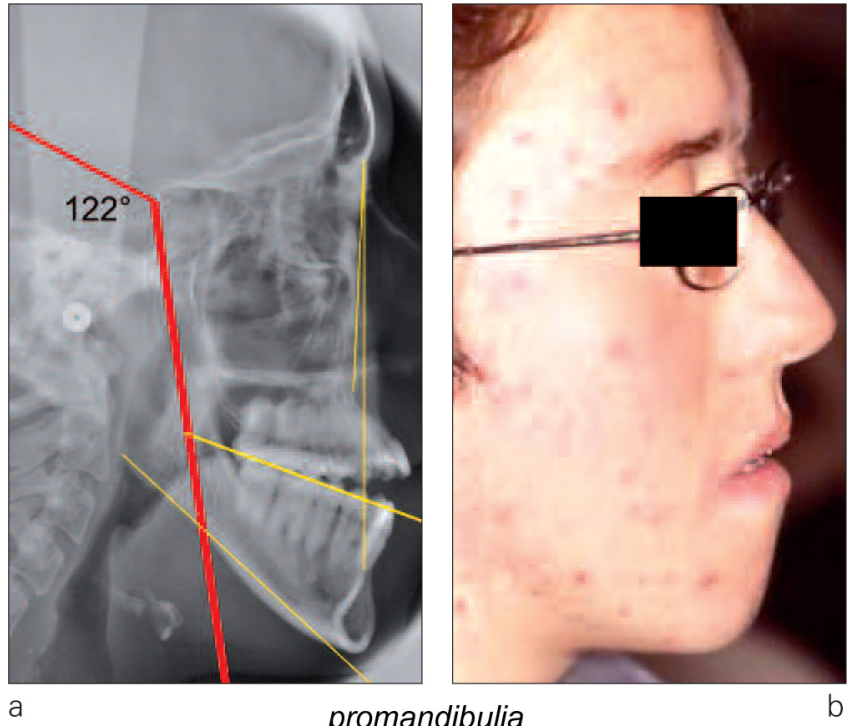

a

promandibulia

Figures $11 a$ and $11 b$

Sylvain D., 19 years old. Genetic factors.

Charcot-Marie-Tooth syndrome.

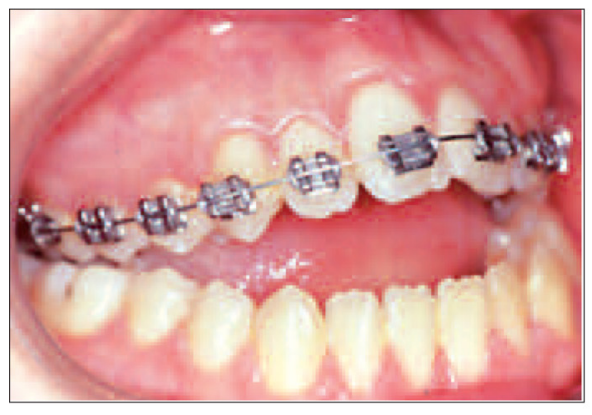

a

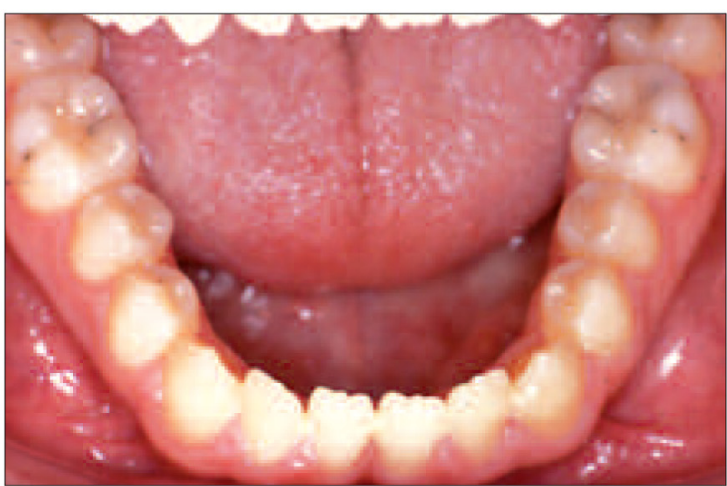

d

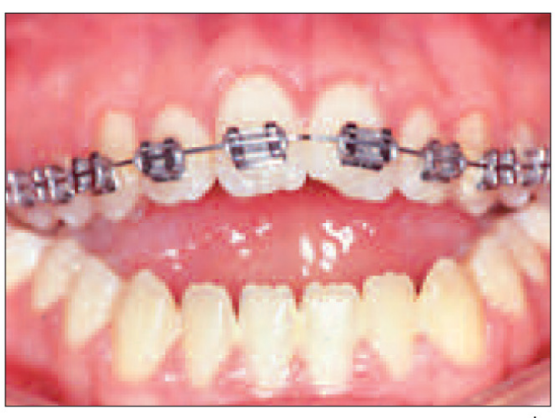

b

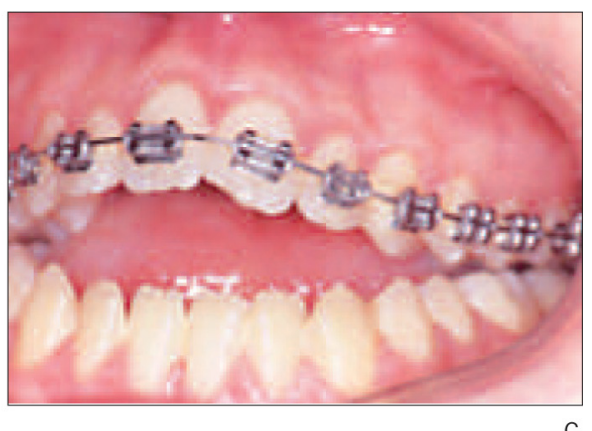

Figures $12 a$ to $12 d$

Sylvain D., 19 years old. Charcot-Marie-Tooth syndrome. 


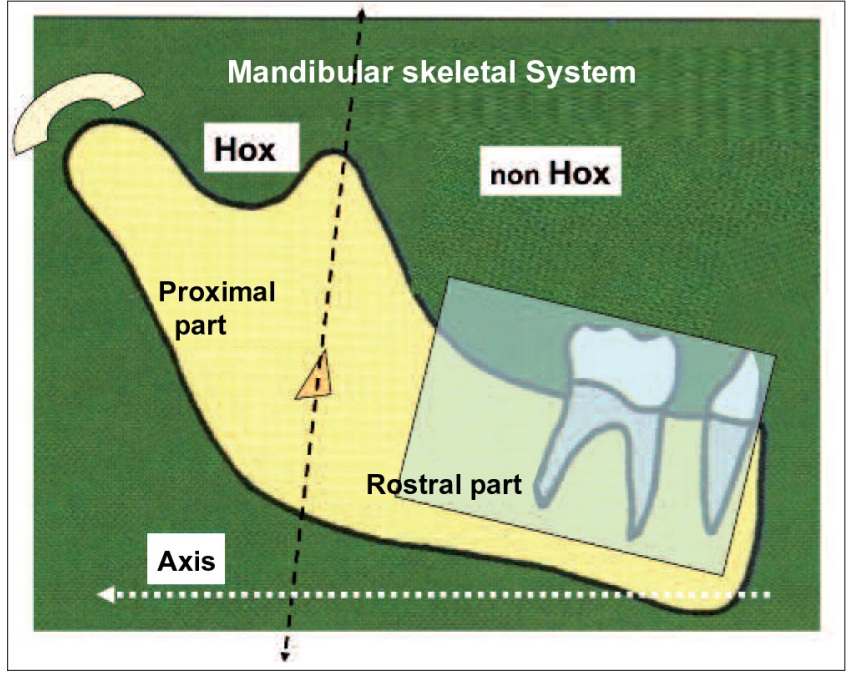

Figure 13

Mandibular system: two different fields.

severe anterior open bite from first bicuspid to first bicuspid and his upper second molars were in cross bite and not in contact with the cheeks.

Sylvain was a full-time mouth breather. His tongue and muscles of mastication were weak. In function, his temporo-mandibular articulation was moderately painful. He has been undergoing orthodontic treatment for several years and is also receiving therapy for Charcot-Marie-Tooth syndrome (arthrodesis of the ankle bones had already been performed and vertebral bone and muscles were also weak).

Supplementary examinations emphasized the maxillo-mandibular Class III deformity as well as the malposition and weakness of the rami. The distance between the wings of the ptyergoid muscles is short. And the naso-maxillary system is atresic.

\section{4 - SYSTEMIC BIOLOGY OF INTERACTIONS OF THE SKELETAL MANDIBLE}

The embryonic development of the mandible is a complex system where the cells of the neural crests and the constituent mesenchymal cells originate different non-Hox and Hox embryonic fields on the antero-posterior axis (fig. 13). This control encourages a differential expression of these two cellular groups at the interior of the first branchial arch ${ }^{11}$.

The different derivatives of the cells of the neural crest are destined to become the basic elements of a number of parts of the masticatory apparatus ${ }^{12}$.

\section{4 - 1 - Skeletalogenesis of the body}

\section{- Origin}

In the non-Hox domain, the most anterior cells of the neural crests: ciencepalic, mesencepahlic, rhombencephalic (R1, R2) originate the future cellular territories of basal bone and of alveolar bone (fig. 14).

\section{- Migration}

These cells of the neural crests migrate into the anterior sector of the first branchial arch under the control of the OTX gene and locate themselves around the incisal nerve under the control of the transcription factors of the MSX and DLX families and the signaling factors ${ }^{25}$ (fig. 14).

\section{- Differentiation}

The cells of the neural crests differentiate into chondroblasts and osteoblasts. Next membranous bone begins to form around the Meckel cartilage under the direction of the transcription factor families MSX, DLX, Gsc, and other signaling factors like BMPs (fig. 14). 


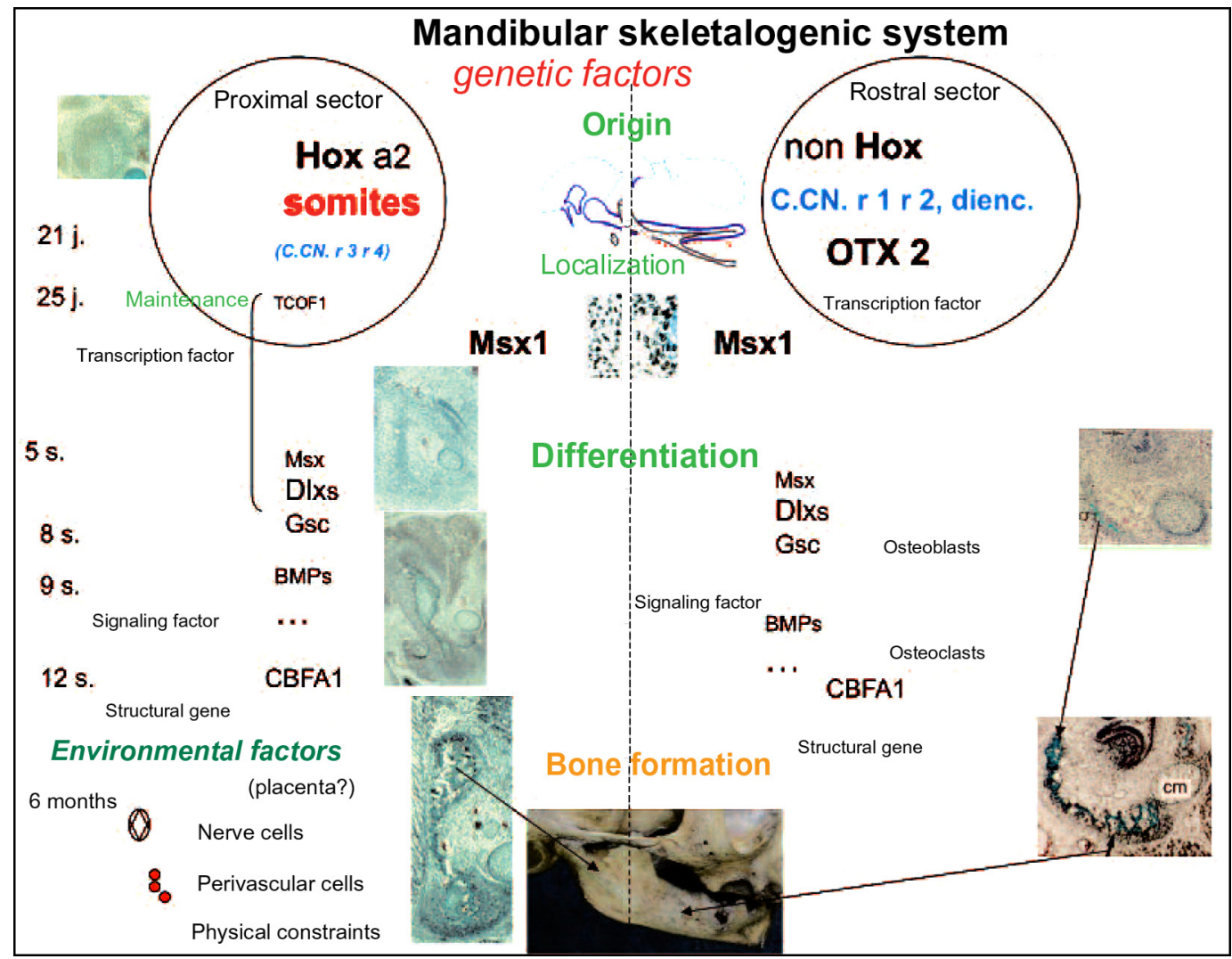

Figure 14

Mandibular skeletalogenic system: genetic factors.

Note: Meckel's cartilage being in certain sectors enveloped in embryonic bone, it is currently thought that it is progressively resorbed and replaced by the extension of membranous ossification in contact with it.

\section{$4-2$ - Skeletalogenesis of the ramus}

\section{- Origin}

In the HOX (Hoxa 2) domain the population of cells derives its origin from the para-axial mesoblast in proximity to rhombomeres R3 and R4 (fig. 14).

\section{- Localization}

After the fifth week the localization in blastemas of sectors destined to develop cartilage and bone is associated with the genes MSX1 and DLX1 working together with signalization factors (fig. 14).

Note: at the same time, populations of cells whose destiny is aponeurosis formation congregate nearby (see the next chapter.)

\section{- Differentiation}

Genes MSX1, DL1, and Gsc and signalization factor BMP1 control differentiation between chondroblasts 


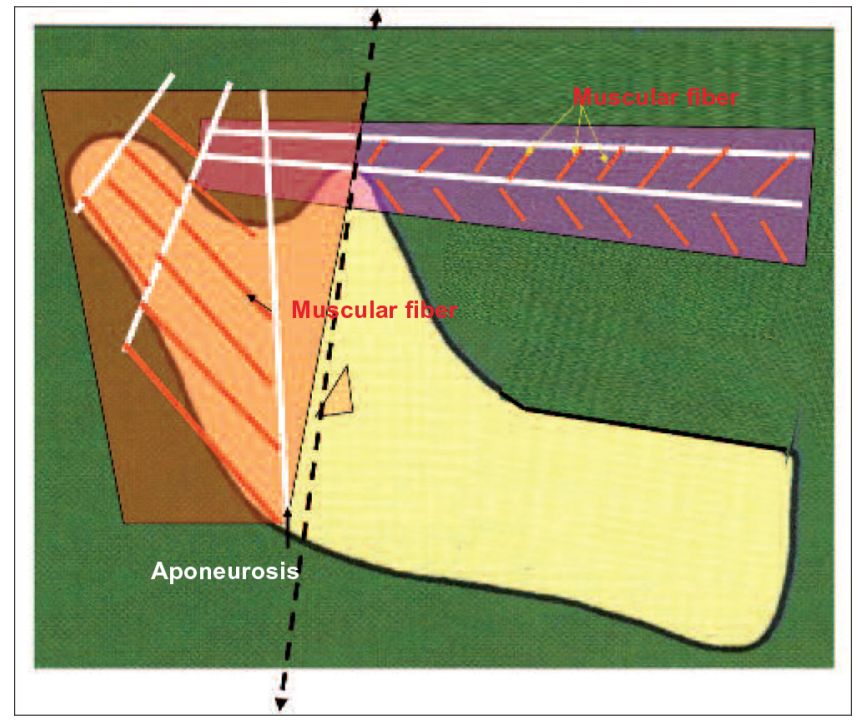

Figure 15

Interactions of the aponeurotic-muscular system.

(secondary cartilage) and osteoblast (fig. 14)
Note: The gene CBFA1 activates calcification.

\section{5 - INTERACTIONS IN APONEUROSIS-MUSCULATURE BIOLOGY}

\section{$5-1$ - Cells of the neural crests}

\section{- Origin}

The cooperation of the cells of the neural crests of rhombomeres R3 and R4 will be needed for building the composite structures of muscles of mesodermal origin in forming the connective tissue component as well as the tendons of the aponeuroses that will bind them to skeletal segments. The gene HOXa2 ${ }^{11}$ controls these cells of the neural crests (fig. 16).

During their migration the neural crest cells destined to become intra and extra connective muscular tissue depend on a transcription factor that assures their maintenance, the factor
TCOF1 that is located on chromosome 5 in q 3-2 or q 3-2, $-1^{2}$.

\section{- Localization}

In the blastema stage after the fifth week of fetal life humans begin the localization of conjunctive and pre-aponeurotic cells in association with the expression of genes of the MSX and DLX families interacting with the regulator genes of the preceding stages ${ }^{23}$.

The cellular populations of the neural crests interact with the mesodermal cells that they encounter to create a coherent system that is responsible for the spatial configuration of each muscle through the intermediary of the aponeuroses and the 


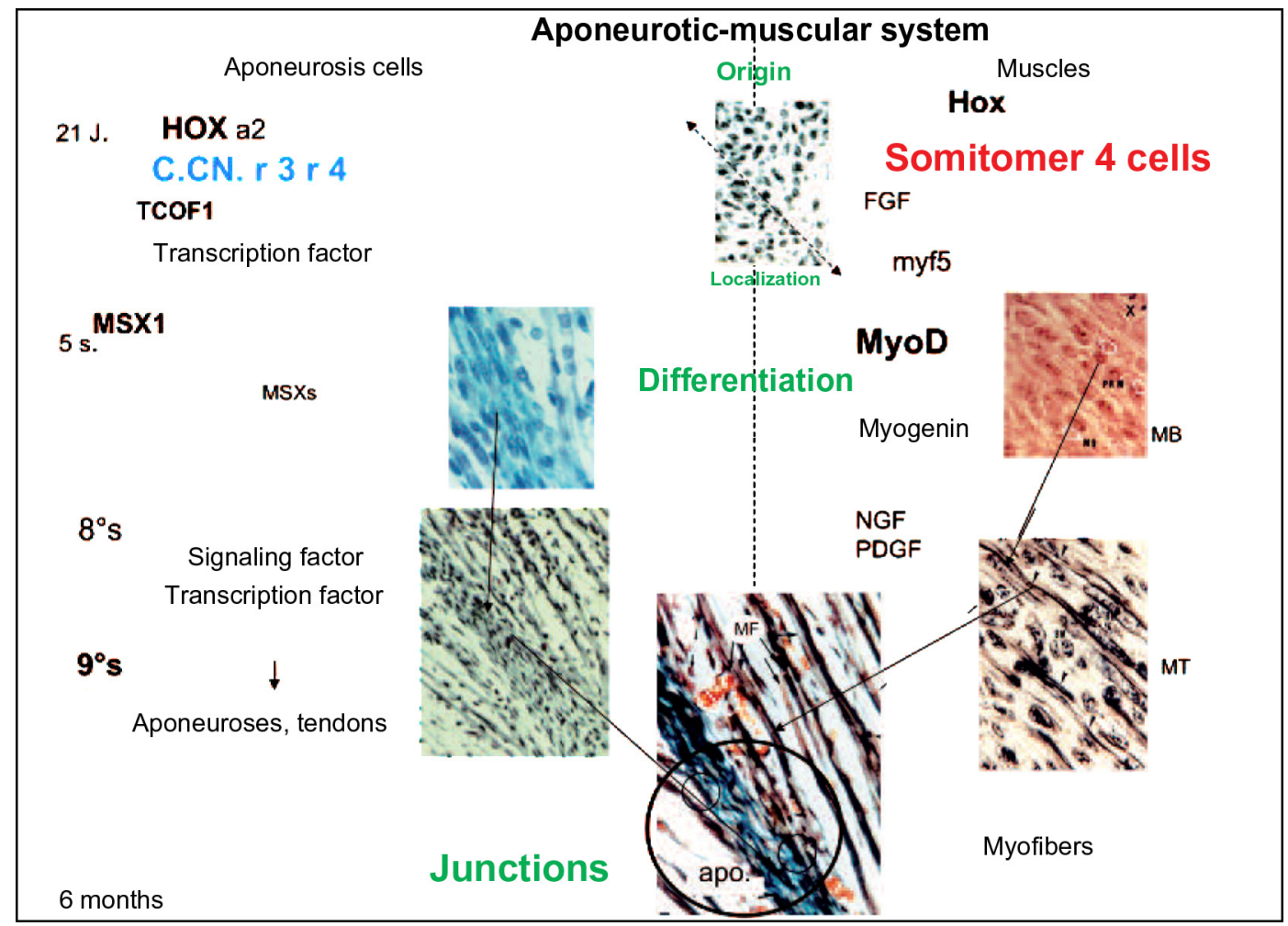

Figure 16

Aponeurotic-muscular system.

attachments on the skeletal crests (fig. 16).

\section{- Differentiation}

The differentiation of the central nervous system in humans begins between the fifth and the eighth week of fetal life probably under MSX1 and signaling factor direction. These central nervous system cells organize themselves in columnar form in several layers prefiguring the future aponeuroses ${ }^{5}$ (fig. 16).

\section{5 - 2 - The para-axial mesoblast (somitomeric)}

\section{- Origin}

The para-axial mesoblast located at the level of somitomer 4 will be the starting point for future myoblastic cells destined to become the muscles of mastication, the masseter, the temporal, and the medial and lateral ptyergoids as well as the accessory masticatory muscles, the mylohyoid and he anterior belly of the digastric.

To be more specific about this origination, many actions intervene between the stage of the para-axial mesoblast, the neuroectoderm, and the ectoderm under the effect of signaling factors like BMP and $\mathrm{Wnt}^{22}$ (fig. 16).

\section{- Localization}

After migration, within the blastema, FGF, the fibro-blastic growth factor, is one of the principal stimulators 
of the multiplication of the two populations of central nerve and somitomeric cells. FGF is, at this stage, capable of inactivating the transcription protein MYoD. The differentiation is not completed until after the loss of the membranous receptors of the fibroblastic growth factors on these embryonic cells.

\section{- Differentiation: $6^{\text {th }}$ to $8^{\text {th }}$ week}

The signaling of MSX1 governs the differentiation of the aponeurotic cells but the differentiation of the myoblastic cells proceeds in another fashion.

The expression of factor myf5, in the muscles of the head, is not specific to a given population of branchial myoblasts, extra-ocular or facial ${ }^{22}$. Thereafter, proteins of the Myod family commit undetermined cells to a myoblastic differentiation. Next they activate the genes that stimulate specific muscle proteins under the control of another transcription factor, myogenine, a member of the Myod family, which is also indispensable for fusion of the myoblasts ending in the primary myotube $\mathrm{MT}^{20}$ (fig. 16).

Experiments with myogenin in mice, however, have shown only the formation of a sparse number of muscle fibers. Myod belongs to the family of transcription factors called myogene proteins or the Myogenesis Regulating Factors family (MRF), the regulators of myogenesis.

At this precise stage of development, the thyroid hormone (tri-iodothyronine: T3) activates the synthesis of the two myogenic factors, Myod and myogenin ${ }^{21}$.

At the end of the ninth week, the innervation of the muscles of mastication begins with the arrival of the axonal terminations of the trigeminal trunk, in the perimysium. The NGF growth factor stimulates these axon cells and surrounds them with a multiplicity of muscular cells in fascia. This new myoblastic cellular proliferation triggers the formation of secondgeneration myotubes, $\mathrm{MT}^{3}$. The histogenic activity in the muscle fascia, with the appearance of the first satellite cells, terminates in the completed organogenesis of the first order muscular and aponeurotic identities.

\section{5 - 3 - Vascularization}

By the end of the $4^{\text {th }}$ week, the first aortic arch has disappeared and in the branchial arches mesenchymal $T$ cells are becoming endothelial cells and blood vessels begin to differentiate from these two cellular sources. They will form in connective tissue compartments of the perimysium during the $6^{\text {th }}$ to $9^{\text {th }}$ weeks to establish the extensive anastomosed network of blood vessels ${ }^{1}$ that the muscles of mastication will eventually enjoy. This abundant basic network of continuous capillaries consists of longitudinal branches parallel to the main axis of connective tissue and branches perpendicular to it. The completed ensemble makes up a dense network of linked capillary chains that will drain the venules and the veins of the perimysium.

\section{5 - 4 - Terminal morphogenesis}

The fibers of the muscles of mastication are cylindrical varying in diameter from 20 to 60,000 u depending on their composition and are 15 to 
$40 \mathrm{~mm}$ in length depending on the muscle and the site. These fibers are enclosed in the sarcolemma, a plasma membrane with an outer coat of thin molecular collagen fibrils that constitutes the basal lamina under which the satellite cells are nested. The endomysium, a thin layer of connective tissue richly invested with widely dispersed capillaries, lies between these fibers. These fibers are grouped in a fascia of 10 to 100 fibers covered with a thicker connective tissue layer called the perimysium that are fixed to bone by tendons whose terminal form is variable.

\section{5 - 5 Integration 1 (fig. 17)}

Until the $12^{\text {th }}$ week the amplification of the zones of anchorage between the muscle fibers and the aponeuroses is characterized by an augmentation of surface contact extended by inter-digitation between the two tissues. The tendons, the aponeuroses, the myotubes, and, later, the myofibers enlarge their surface area in the same way to make

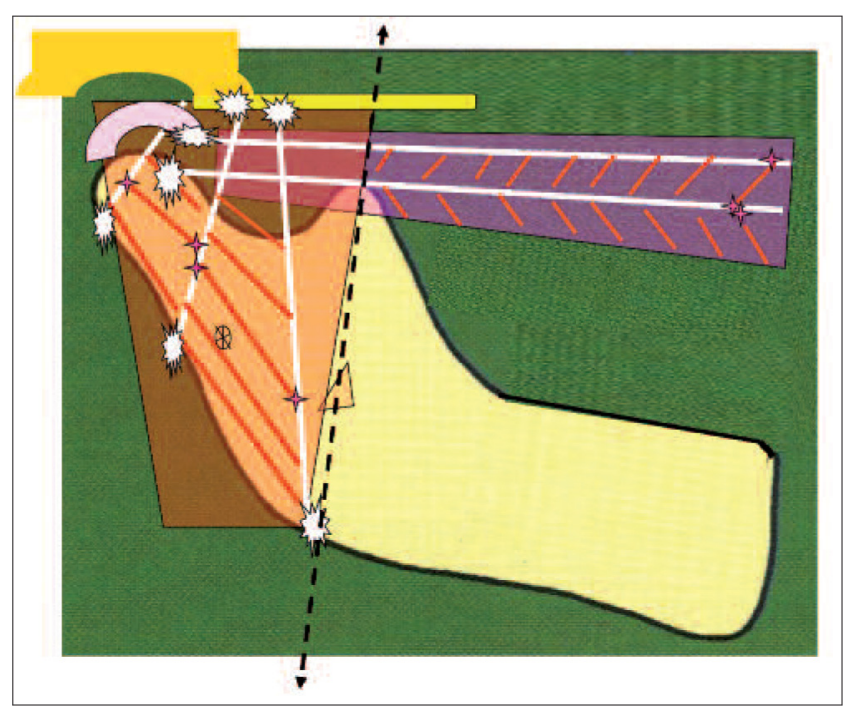

Figure 17

Aponeurosis-skeletal network: integration $n^{0} 1$.

contact with the periosteal cells of the bone being constructed. Thus the tendons and the aponeuroses are associated with the development of the osseous crests.

It seems reasonable to say that, from the beginning, the HOX, KROX, OTX and FGF genes intervene in

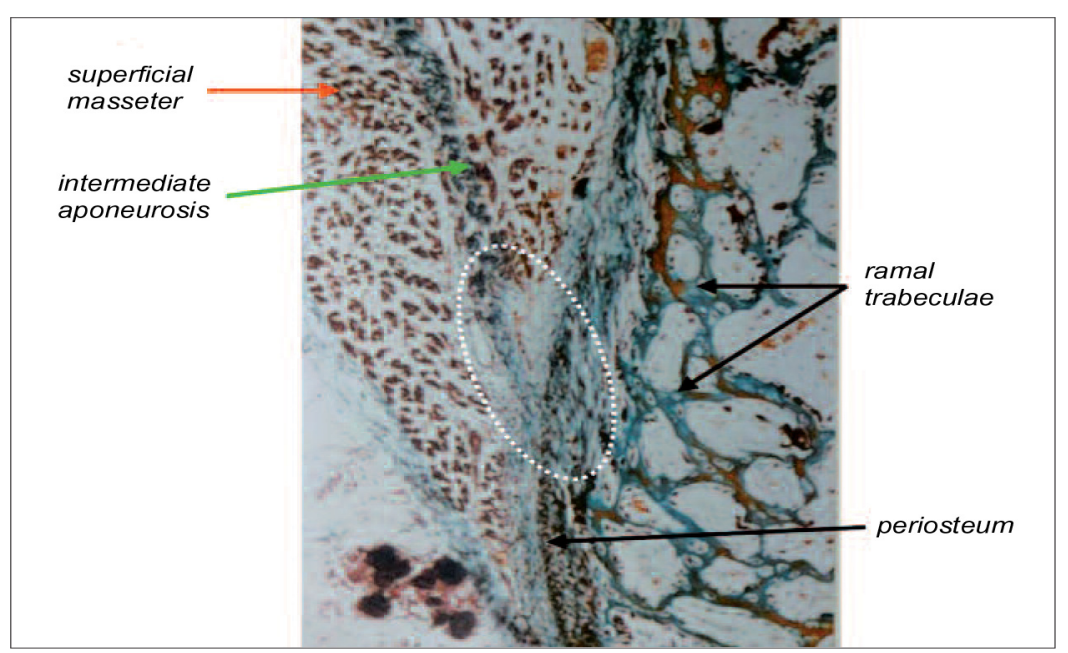

Figure 18

Histological section at 25 days of a rabbit, equivalent of 6 months in humans.

"It seems reasonable to say that, from the beginning, the HOX A2 intervene to inform and position the cells of the neural crests that will take up their positions as future osteoblastic ramal cells and future aponeurosis cells."

Nicole Le Douarin, 2000. 


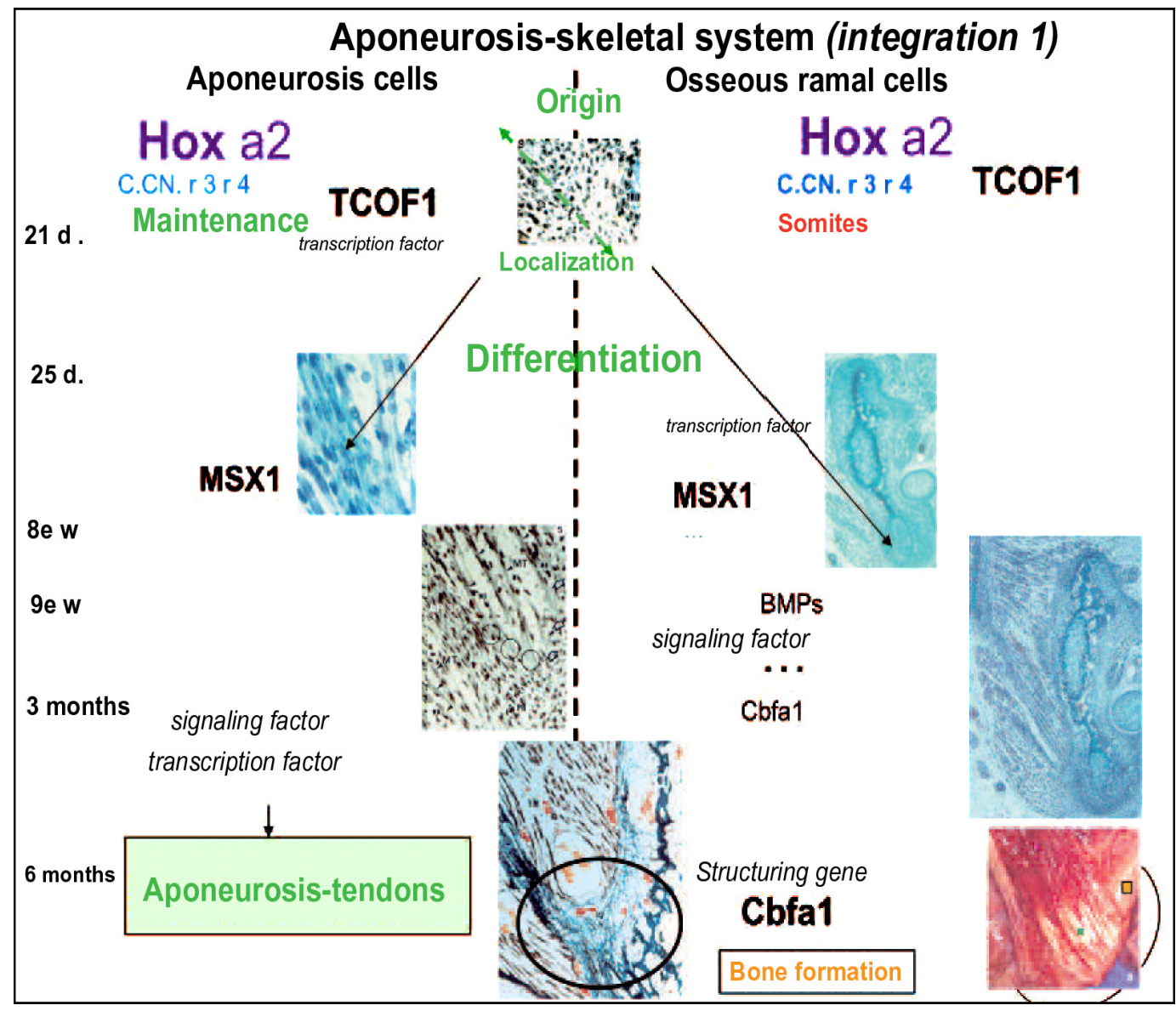

Figure 19

Aponeurosis-skeletal system (integration 1).

collinearity to inform and position the cells of the neural crests that will take up their positions as future chondroblasts and osteoblasts of the proximal sector of the mandible and also at the site of the future intra and extramuscular connective tissue cells of the muscles of mastication ${ }^{18}$ (fig. 18). These cells of the neural crest, accompanied by invading small vessels probably oriented by myocytes from the para-axial mesoblast in each subpopulation to furnish information about orientation and elongation ${ }^{22}$.
These combining associations over time have structural consequences: functional associations form the mechanical basis for an integration of the different branchial muscles, and especially the muscles of mastication that are innervated by the trigeminal nerve, which is itself a product of the same cellular populations of the involved neural crests. Accordingly, each muscle has its own form and its own adaptation to its function (fig. 19). 


\section{6 - BIOLOGY OF THE NEURO-MUSCULAR SYSTEM (INTERACTIONS) (FIG. 20)}

In the seventh week of fetal life the redundant axonal terminations emit a neuro-transmitter, acetylcholine, to aggregate the protein molecules of the receptors on the muscle surface.

The growth factor NGF participates in the epigenetic regulation of the development of the synapse. At this stage other neurotropic proteins like BDNF (Brain Derived Neurotropic Factor) have been established to encourage the survival of nerve endings (fig. 21).

In the ninth week the arrival of the growth cone of the motor nerve on the second-generation myotube MT2

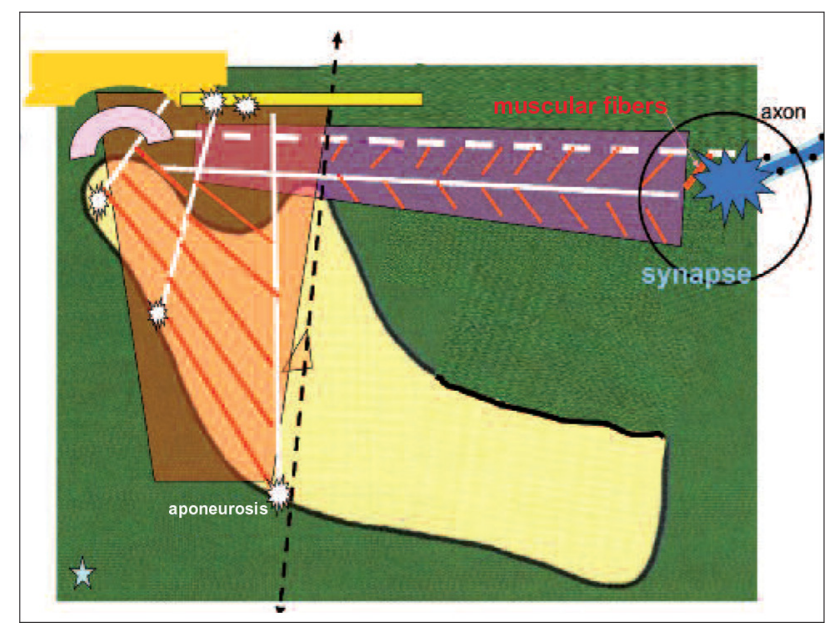

Figure 20

The neuro-muscular system.

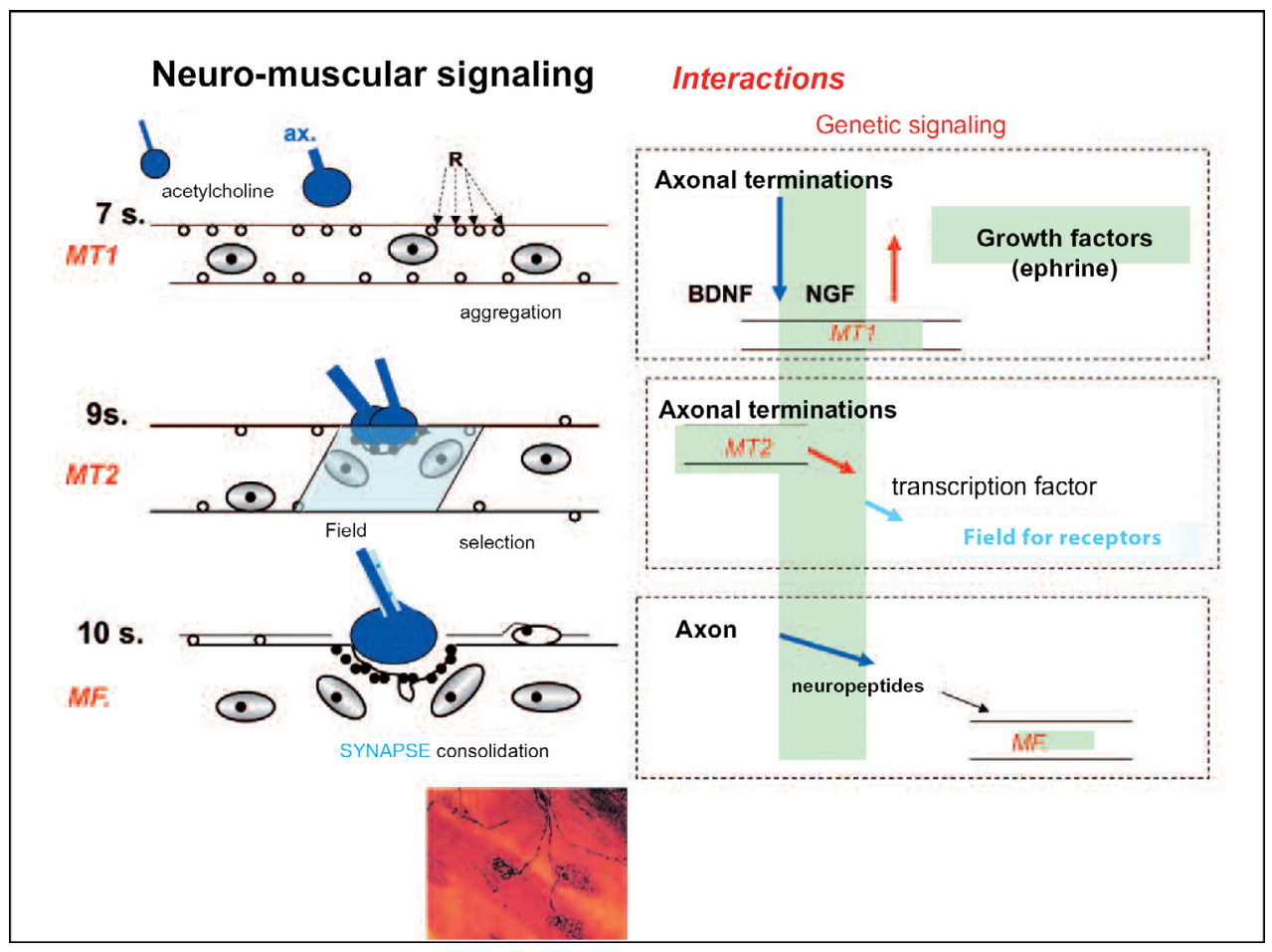

Figure 21

Neuro-muscular system. Interactions. 
sets off the creation and the selective fixation of some receptor molecules under nerve endings with elimination of the other receptors. The synapse function is then stabilized progressively. This morphogenesis and development of the neuro-muscular system is based on a small number of genetic determinants ${ }^{10}$. A transcription factor, the myogenic protein coming from the axonal termination provokes an explosive response in the neuro-muscular field in the secondary myotube. Next, this mechanism is controlled in a positive fashion by neuropeptides released by the nerve endings of the synapse in contact with the myofiber (fig. 21).

\section{6 - 1 Integration 2 (fig. 22)}

In the tenth week the neuro-muscular assemblage is subjected to the epigenetic regulation of electric signals operating in the muscle fiber at many critical moments.

At the interior of the fascia, each muscle fiber continues growing by incorporating new nuclei and by setting enough new sarcomeres in place to allow the muscle fiber to make an epigenetic adjustment necessary for its new capacity to produce a force appropriate to its function. With this strength by the eleventh week the fetus can open and close its mouth. Swallowing capability appears in the twelfth week.

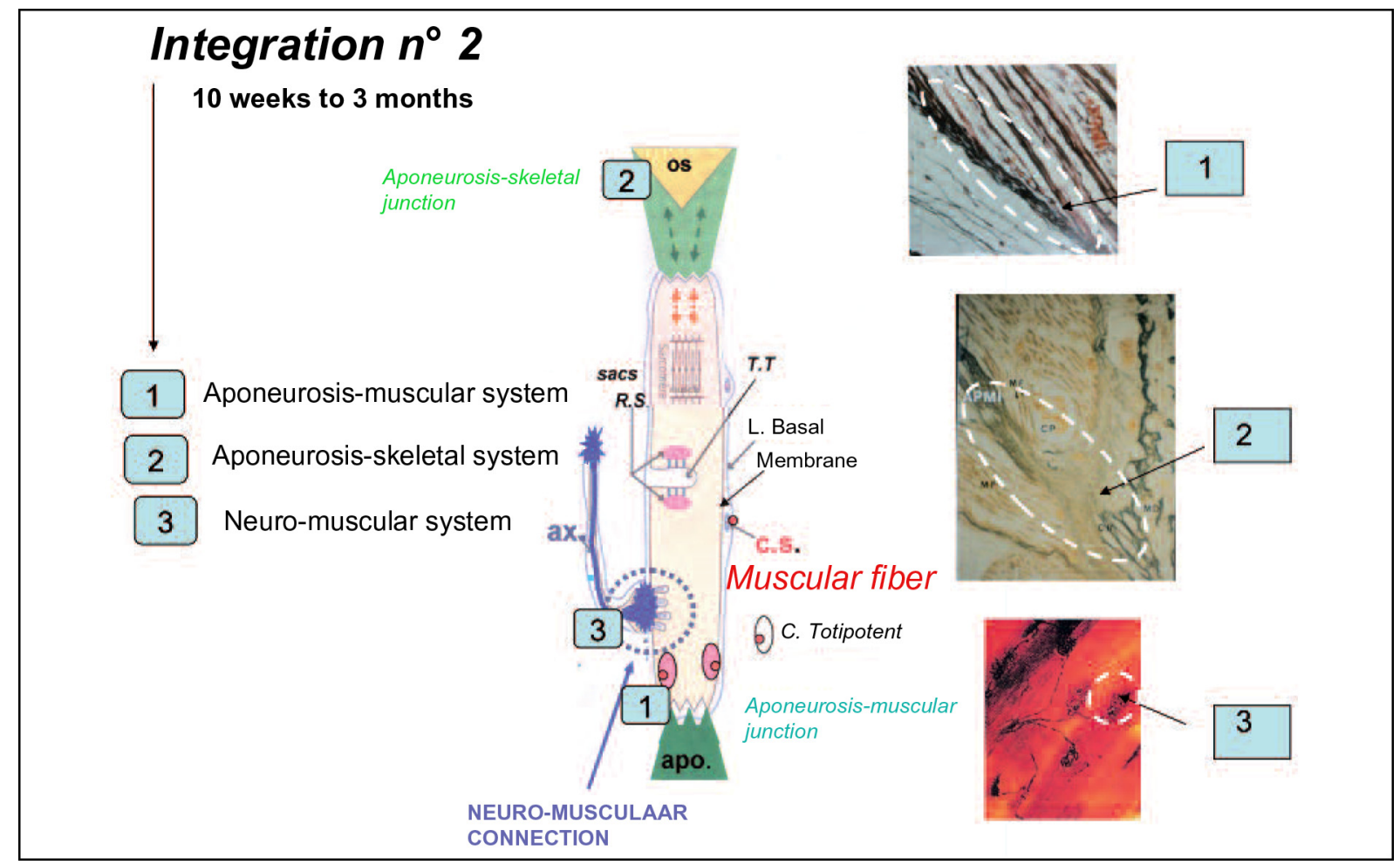

Figure 22

Neuro-muscular system. Interactions. 


\section{6 - 2 - Coordination}

After the neuro-muscular junction has become dependably stabilized, electrical activity, weak at first, commences propagation from the membrane toward the tubules to set off contractions of the muscle fiber sarcomeres in the first movements. Thus a spontaneous but aleatory activity progressively transforms itself into one that is reactional, whose regulation is completed and regulated by neuro-muscular connections.

Muscular tissue contains a great number of sensory receptors:

- neuro-muscular spindles

- Golgi tendon organ receptors that supply the brain with information about the length and the tension of muscles. In this way muscles and tendons are both provided with very sensitive receptors that constitute the sensory organs of the oral cavity. Additional receptors distributed throughout the tem-

\section{7 - THERAPY}

- Christelle, 21 years-old (fig. 23 to 26)

After orthodontic therapy had leveled and harmonized the arches, surgeons performed a maxillary osteotomy of posterior impaction and advancement and a sagittal asymmetric setback osteotomy of the mandible.

Post-operative orthodontic treatment achieved normal inter-digitation of the arches and their integration into the new functional masticatory framework.

Because of the poor relationship between her upper and lower dental poro-mandibular joint complete this sensory chain. After a period of aleatory activity ${ }^{14}$ a reactional and regulated activity is established in this visceral area based on the progressive installation of neuromuscular connections in the group of masticatory, facial, pharyngeal, and tongue musculature that is served by flexible embryonic nerve circuits that are organized in terms of their function.

When these neuro-muscular connections have matured, the integration of these diverse structures in the course of development and the coordination of the different systems can begin.

The nervous system progressively establishes the principal pathways of communication with peripheral structures, the sensory organs for the entrance and the muscles for the exit. It will also set up connections with the groups of peripheral nerve cells, the ganglions.

arches, from the age of thirteen onward Christine had progressively enlarged the masticatory role of the left lateral bundle of the ptyergoid muscle which provoked an osseous adaptation reaction of the left mandibular condyle.

This condylar enlargement created a phenotype, a promandibulia, which therapeutic attitude was caused by a mal-adaptive therapeutic strategy: environmental factors. This situation led to abnormally increased activity of the left bundle of the lateral ptyergoid muscle causing cellular multiplication of the chondrocytes of the left 


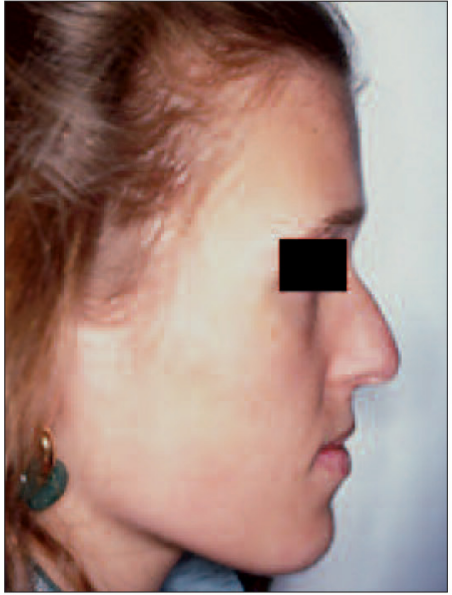

a

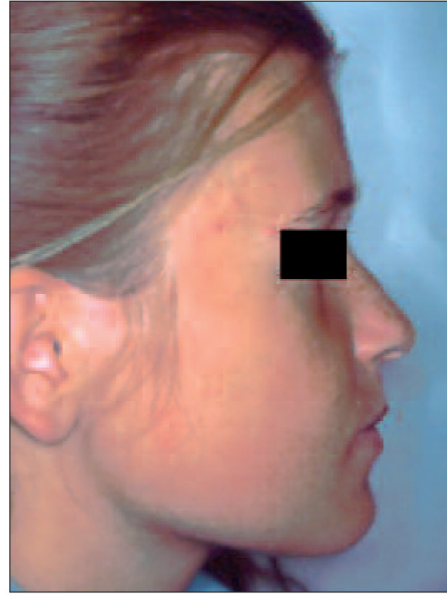

Muscular adaptation to the new skeletal framework

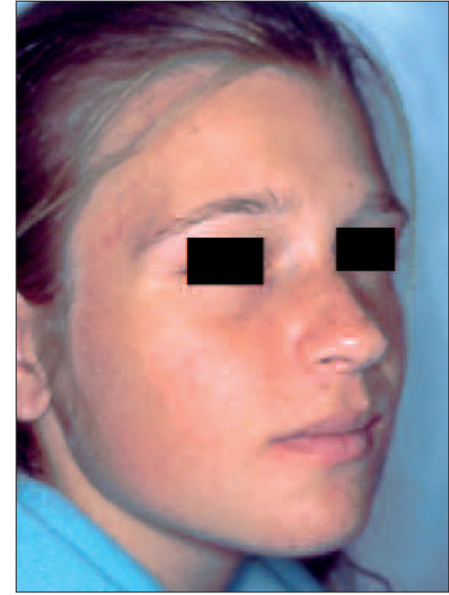

C

Figures 23a to $23 \mathrm{c}$

Christelle C., 21 years old. Environmental factors.
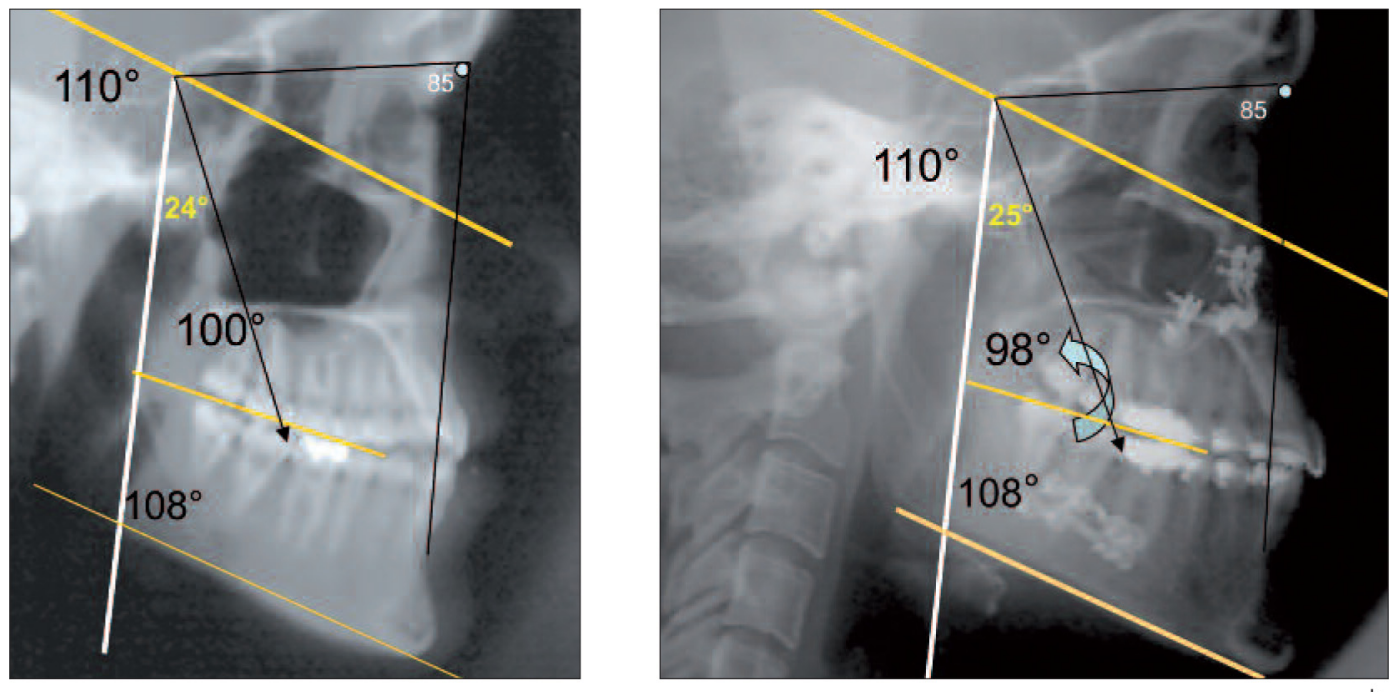

Orthognathic surgery

Figures $24 a$ and $24 b$

Christine C., 21 years old. Environmental factors.

Morphological results after surgical intervention. (TTT: R. Benoit, B. Deffrennes).

condyle and, accordingly its adaptive differentiation and ossification ${ }^{27}$ (fig. 25) that was treated with a combined orthodontic-surgical approach.
This patient ought to have had a suitable preventive treatment and normal neuro-muscular recuperation at a young age. 


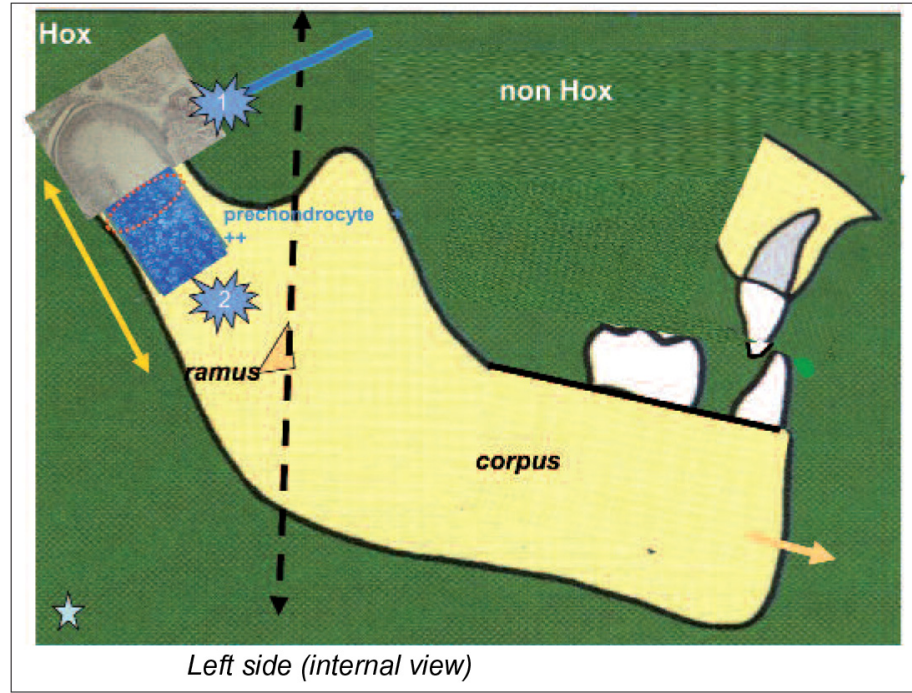

Figure 25

Christine C., 21 years old. Mechanisms.

Therapeutic attitude

Mandible: Integrated systems

Phenotype:

Search for à sencerned gene

-Trouble in neuro-muscular activity

-Skeletalogenic troubles (adaptive)

\section{Environmental factor}<smiles>[CH][CH]</smiles>

Therapeutic responses:

\section{Mechanisms:}

$\mathrm{XX}^{\circ}$ s. Surgery: case by case Symptomatic response

XXI's.
Troubles of inter-arch relationships leading to abnormal muscular activity in a dento-skeletal adaptation

Search for preventive treatment and balanced neuro-muscular recuperation

Figure 26

Christelle C., 21 years old. Therapeutic attitudes.

- Nathalie, 18 years old (fig. 27 to 30)

The objectives of orthodontic treatment for this patient were to level, decompensate, and harmonize the arches. We treated this patient surgically with a bimaxillary Lefort 1 procedure with posterior maxillary 


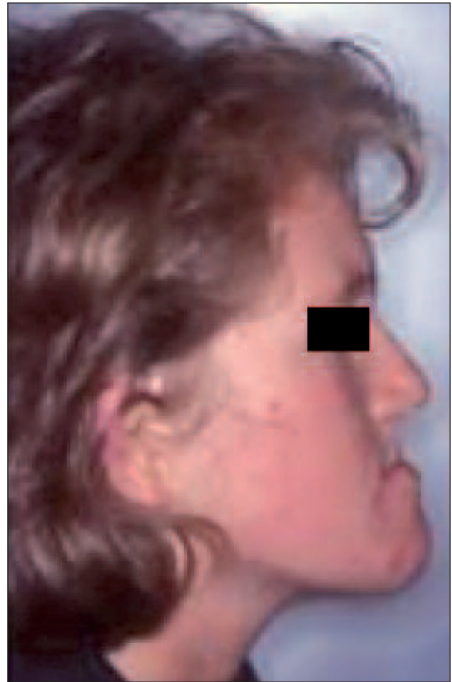

a

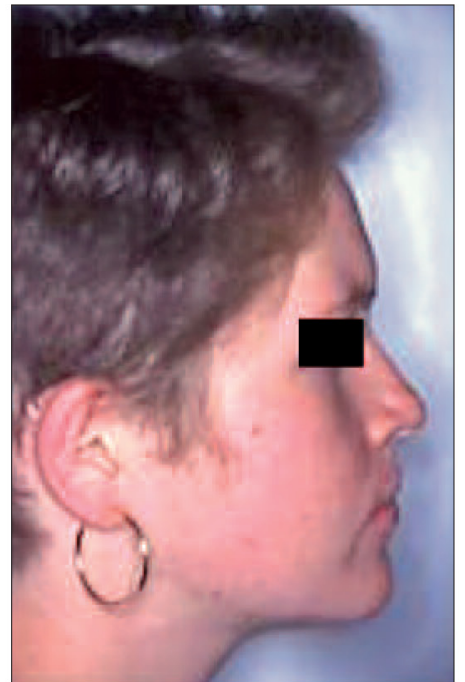

Muscular adaptation and installed skeletal framework

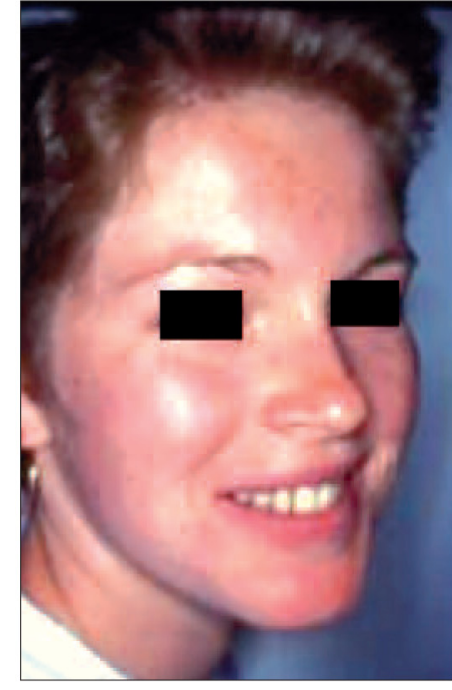

Figures 27a to $27 \mathrm{c}$

Nathalie P., 18 years old. Environmental factors.

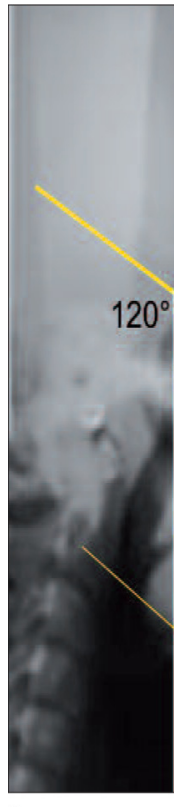

a

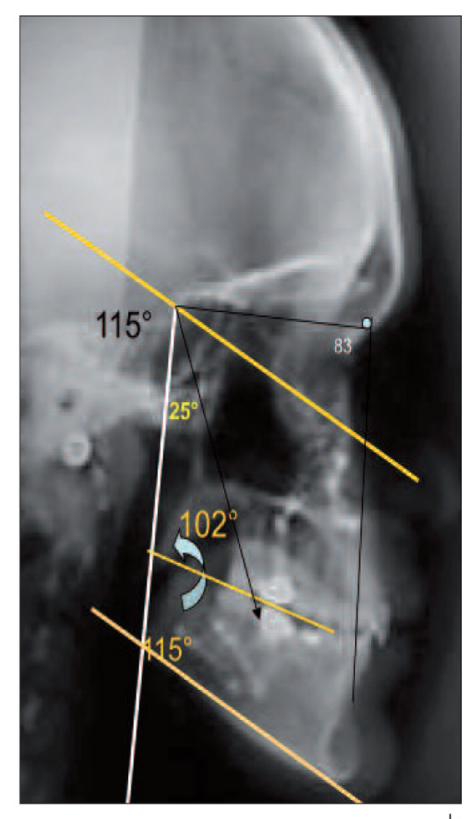

Promandibulia
Figures 28a and 28b Nathalie P., 18-years-old. Genetic factors.

Morphological results after surgical intervention. (TTT: R. Benoit, B. Négrier). impaction accompanied by a sagittal retraction osteotomy of the mandible. Finishing orthodontic treatment achieved better inter-digitation of the arches. We employed upper and lower anterior retention and plan to re- 


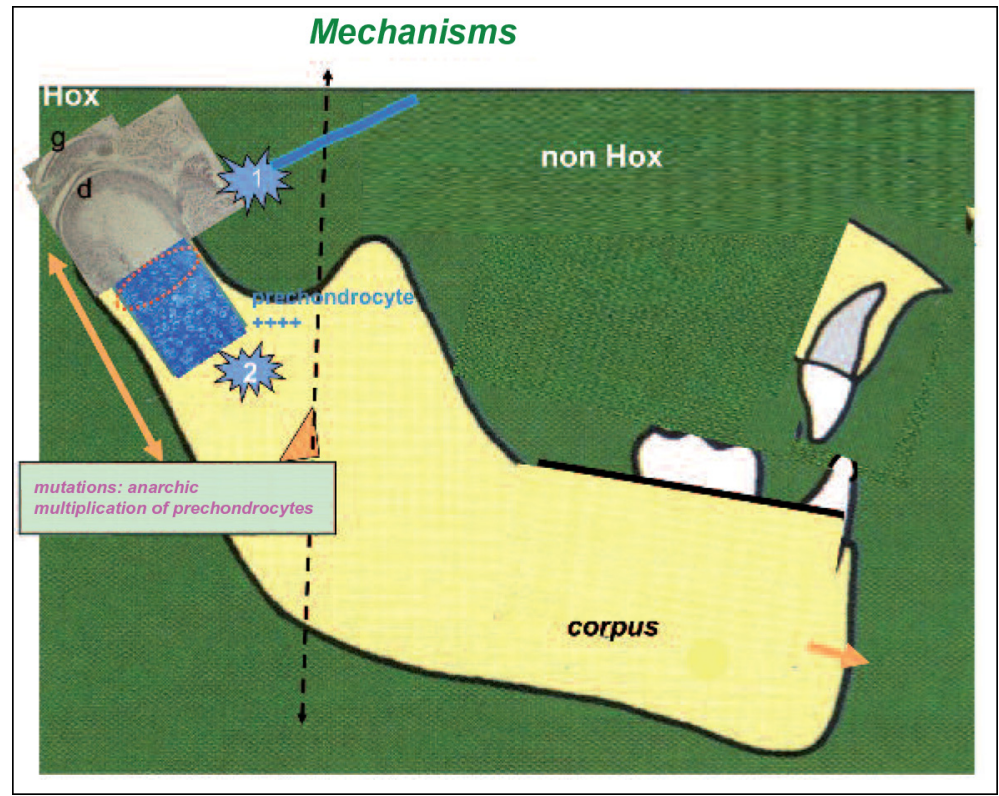

Figure 29

Nathalie $P$., 18 years old. Mechanisms.

Therapeutic attitude

Mandible: Integrated systems

Phenotype:

-Agenesis

-Skeletalogenesis problems

Therapeutic responses:

XX's. Surgery: case by case

Symptomatic response
Search for a concerned gene $1 p 36,6$ q25, 19 p13.2

Mutations: anarchic multiplication of prechondrocytes<smiles>C=[13CH]</smiles>

Mechanisms:

Genetic interactions and integrations in the mandibular systemic biology

$\mathbf{X X I}{ }^{\circ} \mathbf{s}$.

\section{$\rightarrow$ Early diagnosis}

Research to be done!!

Figure 30

Nathalie P., 18 years old. Therapeutic attitudes. 
place the congenitally absent teeth with either implants, prostheses, or biological teeth.

The treating team should study the patient's "information families" to look for the mutations responsible for the deformity. Using the results of this research they can establish an early prognosis and, more confidently, plan a therapeutic strategy designed specifically for these phenotypes. Discerning such at risk patients is today a recognized public health obligation (fig. 30).

- Sylvain 19 years-old (fig. 31 to 34) After completion of orthodontic leveling, harmonizing, and decompensating the two arches, we performed bimaxillary surgical procedures and a genioplasty for this patient. With post-surgical orthodontic finishing treatment we obtained good inter-digitation of the two arches (fig. 33).
Clinically, the Charxor-Marie-Tooth syndrome results from a neuro-muscular disorder that causes muscular atonia, which, in turn, provokes an attack on the bones of the limbs and vertebrae and the mandible. In this case, the rami are more affected than the body. (fig. 33).

\section{Biological origin}

The Charcot-Marie-Tooth (CMT) disease is a hereditary neurological disorder that is estimated to occur at a rate as great as one out of 2500 births in Europe and the United States. It most frequently first manifests itself in children from ten to fifteen years of age, affecting the peripheral nerves connecting the spinal cord to muscles causing them to lose their tone. As a result the spinal cord itself and the feet are affected $^{19}$. Researchers have discerned several modes of CMT transmission,

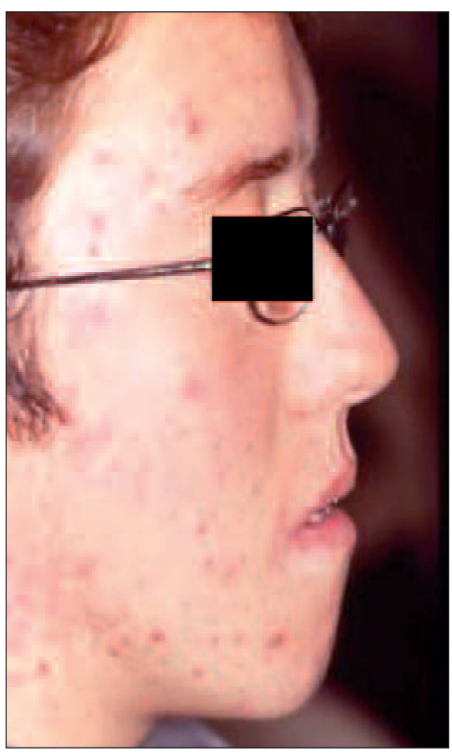

a

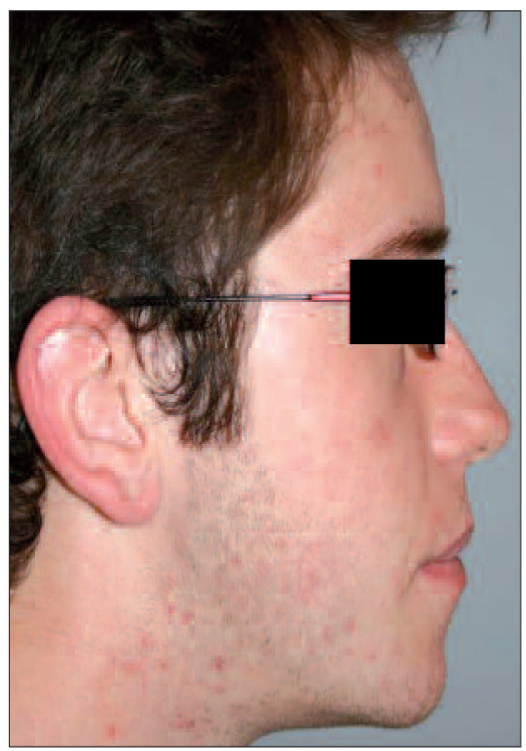

Muscular adaptation to the installed skeletal framework

Figures 31a to $31 \mathrm{c}$

Sylvain D., 19 years old. Genetic factors. Charcot-Marie-Tooth syndrome. 


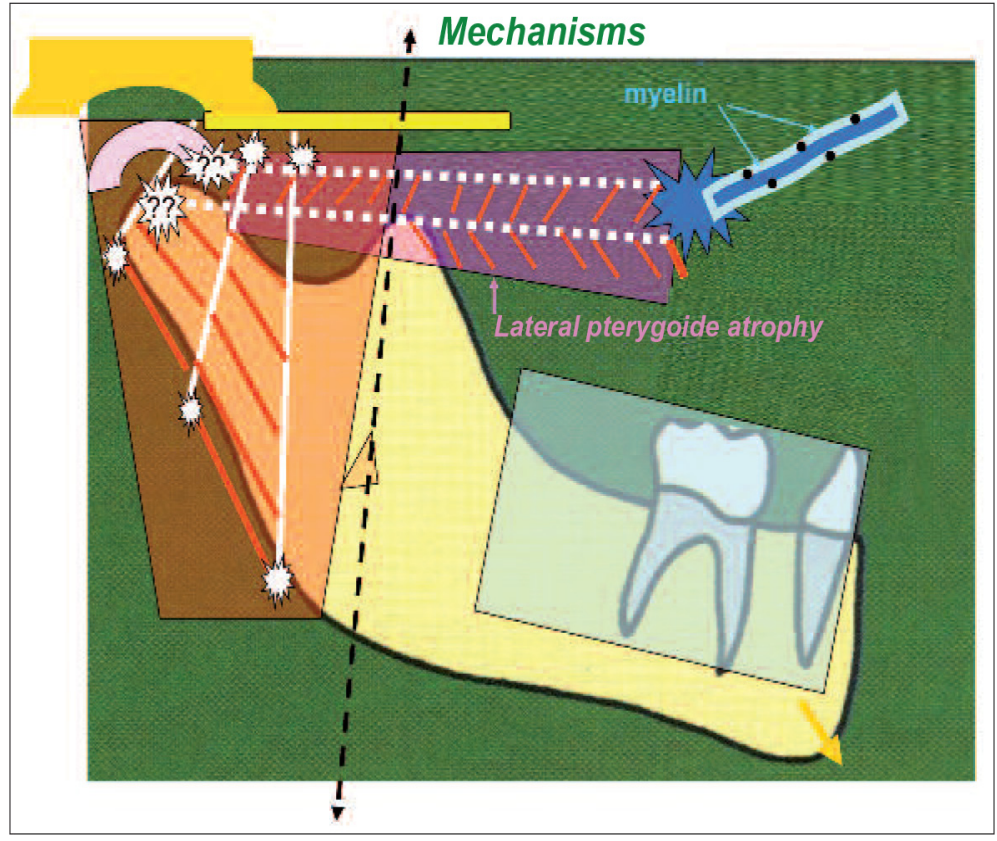

Figure 32

Sylvain D., 19 years old.

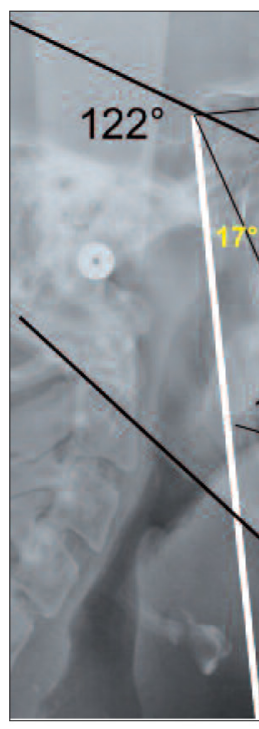

a

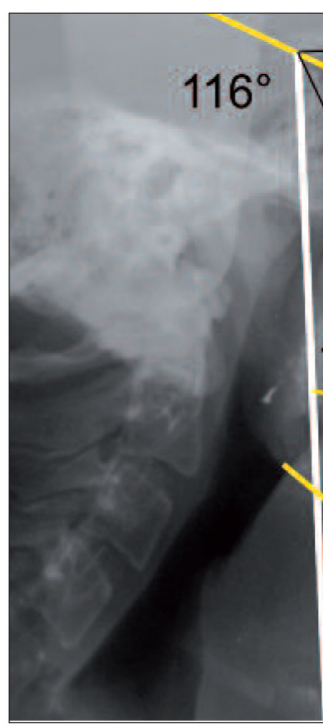

Mechanisms retruded maxilla

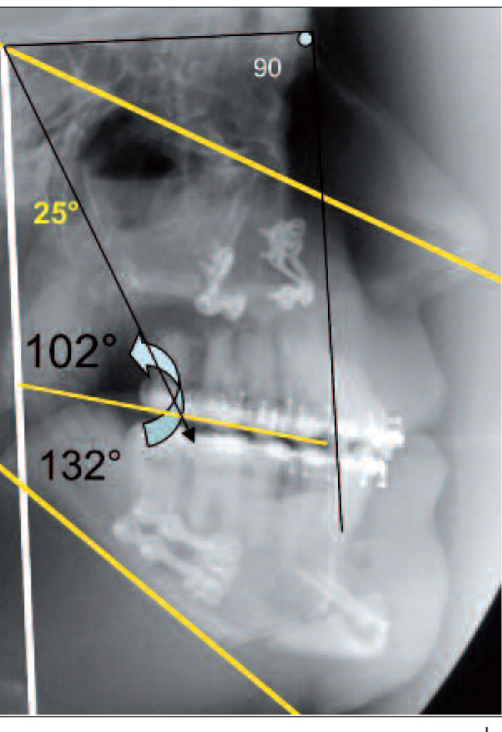

Figures 33a and 33b

Sylvain D., 19 years old. Genetic factors

Morphological results after surgical intervention. 


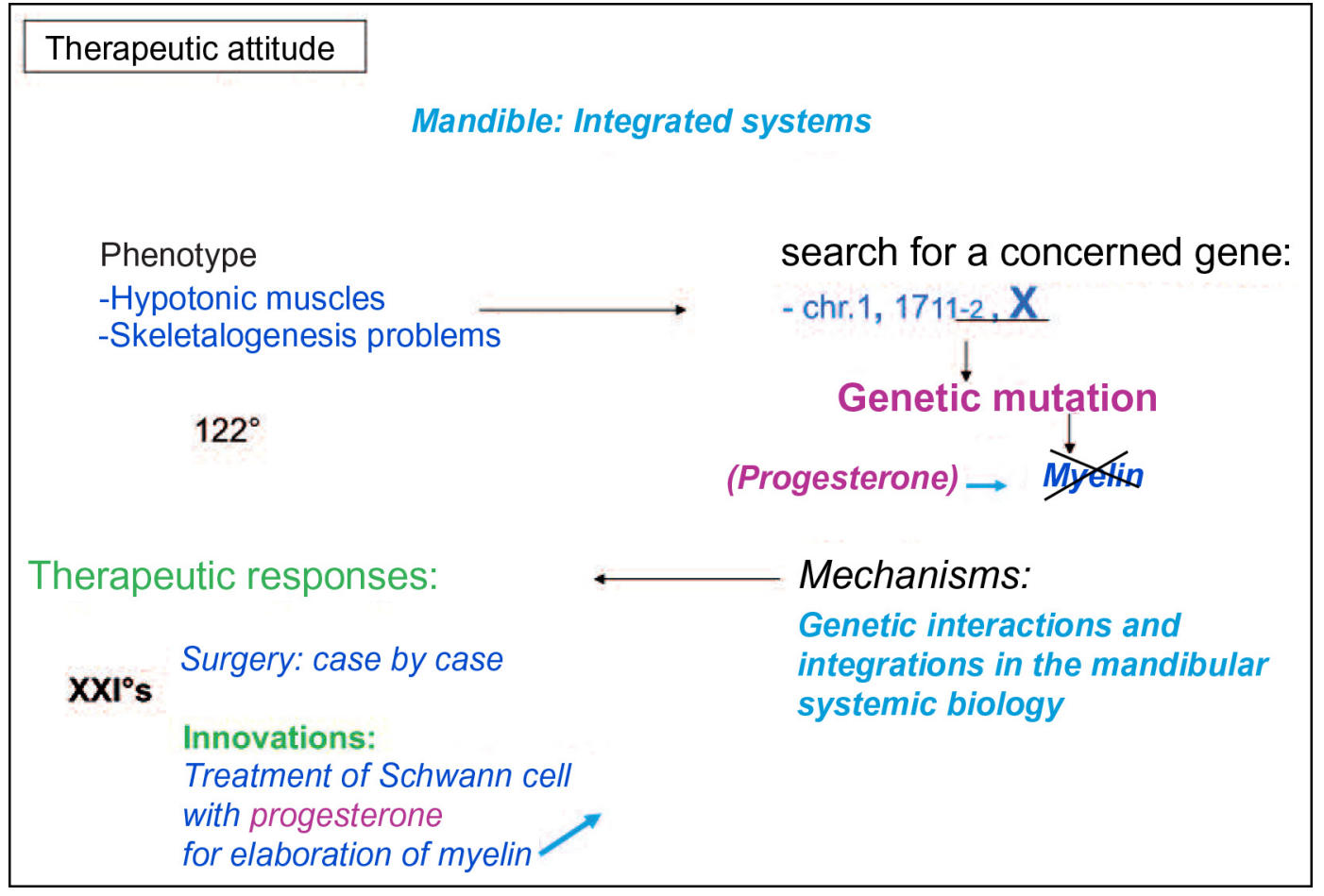

Figure 34

Sylvain D., 19 years old. Therapeutic attitudes.

primarily dominant autosomic related to I'X and recessive autosomic, but many other chromosomes are also suspects. In $70 \%$ of cases, mutations are found on chromosomes 1 , $X, 17$. For the last of these, the identified gene is located on $17 \mathrm{p}-11-2$, which codes for the peripheral myelin protein, PMP.22 that is produced in the Schwann cell in contact with the axon (The French Association Against Myopathy 2009).

\section{8 - CONCLUSION}

In the $21^{\text {st }}$, thanks to the new concept of systems biology, we can better understand the mandibular system before it is integrated into
In this patient it was probably the neuromuscular disorder affecting the muscles of mastication that provoked the faulty development of the ramal bone (fig. 34).

Today, in the 21st century, surgical procedures are still carried out on a case by case basis, but we can hope that it will soon be possible to begin direct Schwann cell progesterone treatment to stimulate the formation of myelin (fig. 34).

the more complex cervico-cranio-facial system. In this more intensive focus on mandibular development we have increased our scientific knowl- 
edge of the role genes play in the functions of transcription and signaling and of the influence of the environmental factors of alimentation, habits, illness, and orthodontic therapy. Not only can we comprehend mandibular development and functioning better, but we have also learned or at least suspected more about "information families" in the genetic etiology of promandibulia, an appropriate field for further investigation. This biological approach can, moreover, be applied to other disorders in cervico-cranio-facial domain. It is reasonable to believe, accordingly, that in the next few years, taking into account the biological knowledge we already have, that genetic therapies will become available. In order for that to happen, our laboratories and our hospital services must continue research on "information families" by means of genetic testing. If a mutation is recognized we can proceed to elucidate the responsibility of this gene or group of genes and propose a therapy to combat it. Today, treatment teams discerning young patients who show early signs of promandibulia can propose appropriate prognoses and treatment strategies or intervene with the type of genetic therapy that is used for the Charcot-Marie-Tooth syndrome.

\section{BIBLIOGRAPHY}

1. Barbet J. P. Le développement du muscle squelettique humain. Doctorat d'état, Paris : faculté des sciences, 1992.

2. Benoît R, Falque $\mathrm{E}$. Ontogenèse et aponévroses des muscles de la face. In : tissus non minéralisés et milieu buccal. In: M. Goldberg Paris: Masson 1993:121-42.

3. Benoît $\mathrm{R}$, Baudoin $\mathrm{C}$. A morphometric investigation of the myotube formation in the rabbit embryo medial pterygoid muscle J Dent. Res 1996;75-11:1835-41.

4. Benoît R. Biologie du développement, génétique cranio-faciale J Edgewise 2001;44: 9-41.

5. Benoît R. Ontogenèse et génétique des muscles masticateurs J. Edgewise 2002;45: 63-97.

6. Benoît R. Ontogenèse et génétique des structures osseuses vertébro-cranio-faciales. Bio Hum Anthropol 2008;26:107-16.

7. Carels C. Concepts sur I'orthodontie du futur: spéculations ou illusions. Ortho Fr 2008;79:49-54.

8. Carvunis AR, Gomez E, ThierryMieg N, Trilling L, Vidal M. Biologie systémique. Des concepts d'hier aux découvertes de demain. Med Sci 2009;25(6-7) :578-84.

9. Changeux JP. L'Homme neuronal. Paris: Fayard, 1983.

10. Changeux JP. L'Homme de vérité. Paris: O. Jacob, 2002.

11. Charrier JB, Bennaceur S, Couly G. Microsomies hémifaciales. Approche embryologique et clinique. Ann Chir Plast Esth 2001;46:385-99.

12. Charrier JB, Creuzet S. Embryologie de la face et dysplasies oto-mandibulaires. Orthod Fr 2007;78:7-24.

13. Deshayes MJ. L'art de traiter avant 6 ans. Ed Cranexplo, 2006.

14. Gaspard M. Acquisition et exercice de la fonction masticatrice chez l'enfant et l'adolescent. Rev Orthop Dento Faciale 2001;35:349-403.

15. Gros F. Une biologie pour le développement. Paris : EDP, 2009.

16. Langlade M. Optimisation des préférences de choix de stratégie thérapeutique. J Edgewise 1999;39:79-95. 
17. Langlade M. The discrimination of the growing risky patient. Prog Orthod 1999: 49-59.

18. Le Douarin N. Des chimères, des clones et des gènes. Paris: O. Jacob, 2000.

19. Le Guen E, Dubourg O. La maladie de Charcot-Marie-Tooth, Encyclopédie Orphanet, 1999.

20. Maire $P$, Bursaux E. La famille des protéines Six, la myogénèse et la myotonie de Steinert. Med Sci 1999;15(2):273-4.

21. Marchal S, Cassar-Malek I, Rodier A, Wrutniak Ch, Cabello G. Mécanismes moléculaires impliqués dans l'activité myogénique de la triiodothyronine (T3) Med Sci 1996;12(10):1065-76.

22. Noden DM, FrancisWest P. The differenciation and morphogenesis of craniofacial muscles. Dev Dyn 2006;235:1194-218.

23. OrestesCardoso S. Etude de MSX1 dans la squelettogenèse craniofaciale à l'aide d'un modèle de souris transgénique. DEA Univ Paris VII, 1998.

24. Raberin M. Morgon L. Gay-Brevet K. Facteurs décisionnels céphalomètriques dans les traitements précoces des classes III squelettiques. Orthod Fr 2007;78:101-112.

25. Roubinet $V$. La recherche clinique en odontologie. Etat des lieux concernant les dispositifs médicaux. Thèse Doct Chir Dent, Lyon, 2006.

26. Vi-Fane B, Fernandes I, Davideau JL. MSX1 et son influence sur la croissance craniofaciale. Orthod Fr 2007;78:39-48.

27. Yamaguchi T, Park SB, Narita A, Maki K, Inoue I. Genome-wide linkage analysis of mandibular prognathism in Korean and Japanese patients, J Dent Res 2005;84(3): 255-9. 